\title{
Society for Immunotherapy of Cancer (SITC) clinical practice guideline on immunotherapy for the treatment of lymphoma
}

\author{
Sattva S Neelapu, ${ }^{1}$ Sherry Adkins, ${ }^{1}$ Stephen M Ansell, ${ }^{2}$ Joshua Brody, ${ }^{3}$ \\ Mitchell S Cairo (D) , J Jonathan W Friedberg, ${ }^{5}$ Justin P Kline, ${ }^{6}$ Ronald Levy, ${ }^{7}$ \\ David L Porter, ${ }^{8}$ Koen van Besien, ${ }^{9}$ Michael Werner, ${ }^{10}$ Michael R Bishop ${ }^{6}$
}

To cite: Neelapu SS, Adkins S, Ansell SM, et al. Society for Immunotherapy of Cancer (SITC) clinical practice guideline on immunotherapy for the treatment of lymphoma. Journal for ImmunoTherapy of Cancer 2020;8:e001235. doi:10.1136/ jitc-2020-001235

Accepted 10 September 2020

Check for updates

(C) Author(s) (or their employer(s)) 2020. Re-use permitted under CC BY-NC. No commercial re-use. See rights and permissions. Published by BMJ.

For numbered affiliations see end of article.

Correspondence to Dr Michael R Bishop; mbishop@medicine.bsd. uchicago.edu

\section{ABSTRACT}

The recent development and clinical implementation of novel immunotherapies for the treatment of Hodgkin and non-Hodgkin lymphoma have improved patient outcomes across subgroups. The rapid introduction of immunotherapeutic agents into the clinic, however, has presented significant questions regarding optimal treatment scheduling around existing chemotherapy/ radiation options, as well as a need for improved understanding of how to properly manage patients and recognize toxicities. To address these challenges, the Society for Immunotherapy of Cancer (SITC) convened a panel of experts in lymphoma to develop a clinical practice guideline for the education of healthcare professionals on various aspects of immunotherapeutic treatment. The panel discussed subjects including treatment scheduling, immune-related adverse events (irAEs), and the integration of immunotherapy and stem cell transplant to form recommendations to guide healthcare professionals treating patients with lymphoma.

\section{BACKGROUND}

Lymphoma is a complex group of diverse diseases that can manifest in many forms under the broad subclasses of classical Hodgkin lymphoma (cHL), B cell nonHodgkin lymphoma (NHL), and T cell NHL, with additional distinction based on the population of lymphoid lineage cells that expand and undergo malignant transformation. Lymphoma affects roughly 870000 people across the US, with an estimated 85720 new cases and 20910 deaths anticipated in 2020 alone. ${ }^{12}$ While a number of modalities have improved outcomes for patients with lymphoma including chemotherapies, radiation, stem cell transplantation, targeted therapies, and immunotherapies, there remains a clear and pressing need to identify novel strategies that can overcome treatment-resistant disease and provide curative potential while minimizing adverse events (AEs).
Numerous immunotherapies have demonstrated efficacy for the treatment of lymphoma and, in some cases, exhibited enhanced benefit when compared with traditional treatment modalities. The immunotherapeutic options approved by the US Food and Drug Administration (FDA) for the treatment of patients with lymphoma include monoclonal antibodies (mAbs), immune checkpoint inhibitors (ICIs), antibody-drug conjugates (ADCs), immunomodulatory drugs (IMiDs), and genetically engineered chimeric antigen receptor (CAR) $\mathrm{T}$ cells. Due to the novelty and relatively recent clinical introduction of these immunotherapies, however, many questions exist concerning optimal treatment scheduling as well as how best to manage and observe patients treated with novel agents.

Previously, the Society for Immunotherapy of Cancer (SITC) formed an expert panel to generate recommendations for the treatment and management of patients with hematological malignancies, including lymphoma, leukemia, and multiple myeloma, which were published in a 2016 consensus statement. ${ }^{3}$ More recently, however, treatment options have significantly expanded across individual disease settings. As such, SITC convened a dedicated expert panel to develop recommendations for the use of immunotherapy in the treatment of lymphoma. The expert panel was charged with generating consensus on optimal treatment scheduling and management of unique immune-related adverse events (irAEs) for FDA-approved immunotherapy agents, and on new technologies that may soon enter the clinic, with the goal of creating a well-supported clinical practice guideline (CPG) for the treatment of lymphoma using immunotherapies. These recommendations are not intended 
to supplant sound clinical judgment but to provide clinicians with the most current thinking on how experts integrate immunotherapy into the treatment of patients with lymphoma. Although differences exist in drug approvals, availability, and regulations in some countries, this panel focused solely on drugs approved by the FDA for the treatment of patients in the US. The full series of SITC CPGs can be found via the SITC website. ${ }^{4}$

\section{METHODS}

\section{SITC Lymphoma Immunotherapy Guideline Expert Panel}

The SITC Lymphoma Immunotherapy Guideline Expert Panel included 12 participants: 9 medical oncologists, 1 pediatric oncologist, 1 nurse practitioner, and 1 patient advocate. All panel members report having experience administering or advocating for cancer immunotherapies including mAbs, ICIs, adoptive cellular therapies, and vaccines. The panel met in person and communicated regularly via email and teleconference, in addition to completing online surveys addressing clinical topics concerning the use of cancer immunotherapy for the treatment of patients with lymphoma, which helped form the basis for the recommendations.

\section{Guideline development process}

The Institute of Medicine's (IOM) Standards for Developing Trustworthy Clinical Practice Guidelines were used as a model to develop the recommendations in this manuscript. IOM standards dictate that guideline development is led by a multidisciplinary team using a transparent process where both funding sources and conflicts of interest are readily reported. Recommendations are based on literature evidence, where possible, and clinical experience, where appropriate. ${ }^{5}$ For transparency, a draft of this consensus statement was made publically available for comment after journal submission. All comments were considered for inclusion into the final manuscript. This consensus statement is intended to provide guidance and is not a substitute for the professional judgment of individual treating physicians.

\section{Evidence and consensus ratings}

Panel recommendations were derived from evidence within the published literature along with responses to a clinical questionnaire that addressed current practices in the use or recommendation for use of immunotherapy agents. SITC Cancer Immunotherapy Guidelines provide recommendations based on peer-reviewed literature and consensus within the expert panel. Consensus was defined as $\geq 75 \%$ agreement among expert panel members.

\section{Conflict of interest policy}

As outlined by IOM standards, all financial relationships of expert panel members that might result in actual, potential, or perceived conflicts of interest were individually reported. Disclosures were made prior to the onset of manuscript development and updated on an annual basis. In addition, panel members were asked to articulate any actual or potential conflicts at all key decision points during guideline development, so that participants would understand all possible influences, biases, and/or the diversity of perspectives on the panel. Although some degree of relationships with outside interests among panel members are to be expected, those with any significant financial connections that may compromise their ability to fairly weigh evidence (either actual or perceived) were not eligible to participate.

Recognizing that guideline panel members are among the leading experts on the subject matter under consideration and guideline recommendations should have the benefit of their expertise, any identified potential conflicts of interests were managed as outlined in SITC's disclosure and conflict of interest resolution policies. As noted in these policies, panel members disclosing a real or perceived potential conflict of interest may be permitted to participate in consideration and decisionmaking of a matter related to that conflict, but only if deemed appropriate after discussion and agreement by the expert panel.

The financial support for the development of this guideline was provided solely by SITC. No commercial funding was received.

\section{Literature review process}

The MEDLINE database was used to search the scientific literature for current therapies related to Hodgkin and NHL and immunotherapy in humans. The literature search was limited to clinical trials, meta-analyses, practice guidelines, and research in humans. The results of the literature search were screened to include only papers with clinically accurate and relevant information and to remove duplicate articles from independent searches. The search was supplemented with additional articles identified by the panel as appropriate and necessary for a comprehensive literature review, resulting in a final bibliography of 241 manuscripts.

\section{GENERAL RECOMMENDATIONS}

Participation in a clinical trial may be a consideration for any patient with lymphoma. Supporting this, a systematic review of patient outcomes determined that participation in a clinical trial, on average, does not result in worse health outcomes for patients. ${ }^{6}$ Because participation in clinical trials does not represent an inherent risk to patient health, participation in clinical trials may be recommended as a matter of routine practice, especially in cases where approved treatment options may be limited.

Initial imaging is an important step in staging lymphoma following diagnosis as well as for monitoring response to treatment. ${ }^{78}$ Evidence from a systematic review supports a combination of fluoro-2-deoxyglucose positron emission tomography (FDG-PET) and computed tomography (CT) as superior to either modality alone in terms of diagnostic performance. $^{9}$ 
Patients being treated for lymphoma may be at increased risk of infection as a consequence of immunosuppression, due to either their disease or immunosuppressive or cytotoxic therapies. For example, rituximab or anti-CD19 CAR T cell treatment may lead to hypogammaglobulinemia, and adoptive cell transfer therapies (eg, CAR T cell infusion) frequently necessitate lymphodepletion. ${ }^{10} 11$ Therefore, it is important to monitor patients for the development of both cytopenias and hypogammaglobulinemia during treatment for lymphoma. ${ }^{12}$

A number of therapeutic agents used in the treatment of lymphoma have the potential to cause cardiotoxicity, including some types of immunotherapy, chemotherapy, particularly anthracycline-based regimens, and radiation. ${ }^{13-15}$ For this reason, a thorough baseline workup for cardiovascular function and regular testing of cardiac parameters is important for any patient undergoing lymphoma treatment. ${ }^{12}$

\section{Panel recommendations}

- There was consensus that clinical trials should be strongly considered as a treatment option at each stage of therapy for eligible patients with lymphoma.

- There was consensus that all patients newly diagnosed with lymphoma should receive initial imaging via FDG-PET-CT.

- There was consensus that patients should be routinely administered complete blood count (CBC) and serum IgG tests. Infection precautions may be considered in patients with decreased neutrophil and absolute lymphocyte counts from CBC tests, as well as low levels of serum IgG.

- There was consensus that all patients with newly diagnosed lymphoma should receive assessment of their cardiovascular history and risk factors prior to receiving potentially cardiotoxic therapies (including some forms of radiotherapy, chemotherapy, and immunotherapies). These patients should be examined and routinely monitored through methods such as transthoracic echocardiogram and ECG based on risk assessment.

\section{HODGKIN LYMPHOMA}

\section{Available agents and indications}

Discussed in the following sections are immunotherapies that have been approved by the FDA for cHL, ordered by history of clinical usage.

\section{Brentuximab vedotin}

Brentuximab vedotin (BV) is an anti-CD30 ADC carrying the antimicrotubule agent monomethyl auristatin $\mathrm{E}$ as a payload. BV has been investigated as a therapy for patients with $\mathrm{cHL}$ and NHL in a number of clinical contexts. For example, in the phase III randomized ECHELON-1 trial (NCT01712490), BV was incorporated into a modification of the doxorubicin, bleomycin, vinblastine, dacarbazine (ABVD) chemotherapy regimen, which has been the established standard of care for the first-line treatment of all stages of cHL for a number of years. ${ }^{16}$ In this study, 1334 patients with previously untreated stage III or IV cHL were administered ABVD or BV with doxorubicin, vinblastine, and dacarbazine (A-AVD) ${ }^{18}$ Patients who received A-AVD exhibited a significantly higher progression free survival (PFS) rate of $82.1 \%$ versus $77.2 \%$ for patients who received ABVD (HR 0.77; 95\% CI 0.6 to 0.98; $\mathrm{p}=0.03$ ) after a median follow-up of 24.9 months. ${ }^{19}$ Patients in the A-AVD group also exhibited higher overall survival (OS) than those in the ABVD group at 24-month follow-up, at $96.6 \%$ versus $94.9 \%$ (HR 0.72; 95\% CI 0.44 to $1.17 ; \mathrm{p}=0.19$ ), although this difference was not significant. ${ }^{19}$ In April 2018, these data supported FDA approval for the use of $\mathrm{BV}$ in combination with doxorubicin, vinblastine, and dacarbazine for the first-line treatment of stage III-IV cHL. ${ }^{20}$

BV has also been approved for use as a consolidation therapy of cHL. In the AETHERA trial (NCT01100502), BV-naïve patients who had received autologous stem cell transplant (autoSCT) and were considered to be at high risk for relapse were administered $\mathrm{BV}$ or placebo. ${ }^{21}$ The median PFS with placebo was 15.8 months, while the median PFS with BV was not reached at 5-year follow-up (HR $0.52 ; 95 \%$ CI 0.38 to 0.72 ).$^{22}$ Based on the AETHERA trial, in 2015, the FDA approved BV as consolidation therapy for cHL patients who have received autoSCT and are at high risk of relapse. ${ }^{20}$

Additionally, BV has been approved for the treatment of relapsed or refractory (R/R) cHL patients who had previously received autoSCT based on a single-arm, phase II study (NCT00848926) where 102 participants who received $\mathrm{BV}$ as monotherapy after relapse had a median PFS of 9.3 months (95\% CI 7.1 to 12.1). ${ }^{23}{ }^{24}$ At 3-year follow-up, OS was estimated to be $80 \%$ (95\% CI $45 \%$ to $100 \%$ ), with an overall response rate (ORR) of $72 \% .{ }^{24}$ These data supported FDA approval in August 2011. ${ }^{20}$

\section{Nivolumab}

The checkpoint inhibitor nivolumab, a mAb that blocks programmed cell death protein 1 (PD-1), has been heavily investigated in solid tumor settings and has also been the subject of therapeutic studies in patients with $\mathrm{R} / \mathrm{R}$ cHL. The phase II, single-arm CheckMate 205 (NCT02181738) and phase I/II, randomized CheckMate 039 (NCT01592370) studies both examined nivolumab monotherapy in patients with $\mathrm{R} / \mathrm{R}$ cHL who had previously received autoSCT and, in some cases, both autoSCT and BV consolidation. ${ }^{25}{ }^{26}$ In a pooled analysis of 243 patients across three cohorts who had disease progression after receiving autoSCT, the ORR for patients treated with nivolumab was $69 \%$ (95\% CI $63 \%$ to $75 \%$ ), the median duration of response (DOR) was 16.6 months (95\% CI 13.2 to 20.3), and the median PFS was 14.7 months (95\% CI 11.3 to 18.5 ). Patients who had previously received both $\mathrm{BV}$ and autoSCT (cohort $\mathrm{C}, \mathrm{n}=100$ ) had an ORR of $73 \%$ (95\% CI $63 \%$ to $81 \%$ ), a median DOR of 14.5 months (95\% CI 9.5 to 16.6), and a median PFS of 11.9 months (95\% CI 11.1 to 18.4 ). ${ }^{27}$ On the basis of 
data from these two trials, the FDA approved nivolumab monotherapy for the treatment of patients with $\mathrm{R} / \mathrm{R} \mathrm{cHL}$ who have received autoSCT and BV, or who have received three or more prior lines of systemic therapy (including autoSCT) in May 2016. ${ }^{28}$

A notable phase II trial, NCT02572167, is examining the combination of $\mathrm{BV}+$ nivolumab in the second-line treatment of R/R cHL. ${ }^{29}$ Interim results from this promising study gave an ORR of $83 \%$ (95\% CI $71.5 \%$ to $91.7 \%$ ) and a complete response (CR) rate of $62 \%$ (95\% CI $48.2 \%$ to $73.9 \%)$ and indicate that this regimen is well-tolerated, although this treatment strategy has not received FDA approval and data on secondary endpoints, including DOR and PFS, are still anticipated. ${ }^{30}$

\section{Pembrolizumab}

Another anti-PD-1 checkpoint inhibitor, pembrolizumab, has been evaluated for efficacy in patients with $\mathrm{R} / \mathrm{R} \mathrm{cHL}$ in the non-randomized, phase II KEYNOTE-087 trial (NCT02453594), which enrolled 210 patients with R/R cHL. ${ }^{31}$ The PFS and OS at 6-month follow-up were $72.4 \%$ and $99.5 \%$, respectively. ${ }^{32}$ The observed ORR was $69.0 \%$ (95\% CI $62.3 \%$ to $75.2 \%) .{ }^{32}$ Based on these data, the FDA granted accelerated approval in May 2017 to pembrolizumab for the treatment of patients with cHL that is refractory or that has relapsed after three or more lines of prior therapy. ${ }^{33}$

\section{Panel recommendations}

- For the first-line therapy of stage I-II (favorable or unfavorable risk) cHL, there was consensus that patients should receive ABVD.

- For the first-line therapy of stage III-IV cHL, the panel did not reach consensus on a single preferred regimen. Options for treatment include ABVD and A-AVD.

- For the second-line treatment of cHL, there was consensus that patients should receive salvage chemotherapy or immunotherapy, and should receive autoSCT, if eligible. Treatment options for preautoSCT chemotherapy or immunotherapy include
BV+bendamustine, ifosfamide+carboplatin+etoposide (ICE), BV+nivolumab, or BV monotherapy. The panel noted that BV is FDA-approved for consolidation treatment following autoSCT, but that the trial supporting this data only examined patients who were BV-naïve, and that $\mathrm{BV}$ consolidation in patients who have previously received $\mathrm{BV}$ is still investigational.

- For the third-line treatment of cHL, the panel did not reach consensus on a single preferred regimen. Options for treatment include salvage chemotherapy or immunotherapy+autoSCT (if transplant-eligible), PD-1 inhibitor therapy, or BV, depending on prior therapies received and patient status.

\section{Therapies in development for $\mathrm{CHL}$}

Ongoing phase III trials (at the time of publication) are examining the safety and efficacy of immunotherapies in new clinical contexts for the treatment of cHL (listed in table 1).

\section{NON-HODGKIN LYMPHOMA}

NHL may be divided into two major categories, B cell NHL and T cell NHL, each of which is comprised of numerous subtypes. Some immunotherapies are approved for a variety of NHL disease states, whereas others are more limited in indication. B cell NHL disease states discussed in this manuscript include diffuse large B cell lymphoma (DLBCL), mantle cell lymphoma (MCL), follicular lymphoma (FL), marginal zone lymphoma (MZL), primary mediastinal B cell lymphoma (PMBCL), Burkitt's lymphoma (BL), and post-transplant lymphoproliferative disorder (PTLD). Discussed in the following sections are immunotherapies that have been approved by the FDA in various NHL disease settings, ordered by history of clinical use.

\section{Available agents and indications \\ Rituximab}

Rituximab is a chimeric anti-CD20 anti-CD20 mAb that has been extensively investigated and used for the

Table 1 Immunotherapies in development for the treatment of Hodgkin lymphoma

\begin{tabular}{llll}
\hline Trial & Agents investigated & \multicolumn{1}{c}{$\begin{array}{l}\text { Agent } \\
\text { description }\end{array}$} & $\begin{array}{l}\text { Primary outcome } \\
\text { for assessment }\end{array}$ \\
\hline CheckMate 812 (NCT03138499) & $\begin{array}{l}\text { Nivolumab+BV vs BV monotherapy in patients with ICl, ADC } \\
\text { R/R cHL, not eligible for autoSCT }\end{array}$ & PFS \\
$\begin{array}{l}\text { NCTN S1826 } \\
\text { (NCT03907488) }\end{array}$ & $\begin{array}{l}\text { Nivolumab+AVD vs BV+AVD (A-AVD) for first-line } \\
\text { treatment of stage III or IV cHL }\end{array}$ & $\mathrm{ICl}$ & $\mathrm{PFS}$ \\
$\begin{array}{l}\text { MK-3475-204/KEYNOTE-204 } \\
\text { (NCT02684292) }\end{array}$ & $\begin{array}{l}\text { Pembrolizumab vs BV for R/R cHL } \\
\text { NCT02572167 }\end{array}$ & $\mathrm{ICl}$ & $\mathrm{PFS,} \mathrm{OS}$ \\
& $\mathrm{BV}+$ nivolumab for R/R cHL & $\mathrm{ICl}, \mathrm{ADC}$ & $\begin{array}{l}\text { Rate of AEs, CR } \\
\text { rate }\end{array}$ \\
\hline
\end{tabular}

A-AVD, brentuximab vedotin, doxorubicin, vinblastine, dacarbazine; ABVD, doxorubicin, bleomycin, vinblastine, dacarbazine; ADC, antibodydrug conjugate; AEs, adverse events; BV, brentuximab vedotin; $\mathrm{CHL}$, classical Hodgkin lymphoma; $\mathrm{CR}$, complete response; ICI, immune checkpoint inhibitor; mAb, monoclonal antibody; OS, overall survival; PFS, progression-free survival; R/R, relapsed or refractory. 
treatment of patients with B cell NHL. In NHL Studies 1,2 , and 3, patients with $\mathrm{R} / \mathrm{R}$, low grade or follicular $\mathrm{B}$ cell NHL were administered rituximab as a single agent with ORR of $48 \%, 57 \%$, and $38 \%$, respectively. ${ }^{34-36}$ On the basis of data from these trials, in November 1997, the FDA approved the use of rituximab for the treatment of $\mathrm{R} / \mathrm{R}$, low grade or follicular CD20+ B cell NHL. ${ }^{37}$

Rituximab has also been evaluated for the first-line treatment of FL (in combination with cyclophosphamide, vincristine, prednisone (CVP)). NHL Study 4 randomized patients with previously untreated FL to receive CVP or rituximab+CVP (R-CVP) ${ }^{38}$ Patients receiving rituximab had a PFS of 2.4 years, compared with 1.4 years without rituximab (HR 0.44; 95\% CI 0.29 to $0.65 ; \mathrm{p}<0.0001) .{ }^{38}$ Rituximab was additionally evaluated as a maintenance therapy for patients achieving response following treatment with rituximab-containing chemoimmunotherapy or chemotherapy alone. In NHL Study 5 (PRIMA, NCT00140582), patients with FL who reached response after initial treatment with rituximabchemotherapy were randomized to rituximab maintenance or no additional therapy. ${ }^{39}$ Patients who were administered rituximab as maintenance had a higher PFS than patients who received no additional therapy after a median follow-up of 36 months, at $74.9 \%$ versus $57.6 \%$, respectively (HR 0.55 ; $95 \%$ CI 0.44 to 0.68 ; $\mathrm{p}<0.0001$ ). ${ }^{40}$ In NHL Study 6 (ECOG 1496), patients with B cell NHL who responded after initial treatment with CVP chemotherapy were randomized to rituximab maintenance or no additional therapy. ${ }^{41}$ Rituximab maintenance resulted in a longer median PFS, at 4.3 years versus 1.3 years for patients not administered rituximab (HR 0.4; 95\% CI 0.3 to $\left.0.5 ; \mathrm{p}=4.4 \times 10^{-10}\right) .{ }^{41}$ In September 2006, the results of NHL Studies 4, 5, and 6 formed the basis of FDA approval for the administration of rituximab in patients with FL as combination first-line therapy with chemotherapy and as maintenance therapy following response in patients with FL who received rituximab-containing combination chemotherapy. ${ }^{37}$ These studies also formed the basis of FDA approval for the use of rituximab as a maintenance therapy for patients with low grade, CD20+ B cell NHL following initial CVP chemotherapy. ${ }^{37}$

Rituximab has been investigated in the treatment of DLBCL, a specific subtype of B cell NHL. During NHL Studies 7 (ECOG-4494, NCT00003150), 8 (GELA LNH-98.5), and 9 (MInT, NCT00064116), patients with previously untreated DLBCL received either cyclophosphamide, doxorubicin, vincristine, prednisone (CHOP) or rituximab+CHOP (R-CHOP) therapy. ${ }^{42-44}$ In all three trials, R-CHOP provided increased PFS when compared with CHOP. In Study 7, PFS was 53\% for R-CHOP and $46 \%$ for CHOP at 3-year follow-up (HR 0.78; 95\% CI 0.61 to $0.99 ; \mathrm{p}=0.04$ ) ${ }^{45}$ In Study 8, event-free survival (EFS) was $57 \%$ for R-CHOP and $38 \%$ for CHOP at 2 year follow-up (HR 0.58; 95\% CI 0.44 to 0.77; $<<0.001$ ). ${ }^{43}$ In Study 9, EFS was $79 \%$ for R-CHOP and $59 \%$ for CHOP (log-rank $\mathrm{p}<0.0001) .{ }^{46}$ On the basis of data from these trials, in February 2006, the FDA approved the use of R-CHOP for the first-line treatment of DLBCL. ${ }^{37}$ PMBCL, a subtype of DLBCL, has also been successfully treated with rituximabchemotherapy combination regimens. A phase II clinical trial (NCT00001337) found that patients $(n=51)$ treated with dose-adjusted etoposide, prednisone, vincristine, cyclophosphamide, and doxorubicin with rituximab (DA-R-EPOCH) experienced an OS rate of 97\% (95\% CI $81 \%$ to $99 \%$ ) and EFS rate of $93 \%(95 \%$ CI $81 \%$ to $98 \%)$ at a median follow-up of 63 months. ${ }^{47}$ A retrospective analysis $(\mathrm{n}=156)$ reported an estimated 3-year OS rate of 95.4\% (95\% CI $91.8 \%$ to $99.0 \%$ ) and EFS rate of $85.9 \%$ $(95 \%$ CI $80.3 \%$ to $91.5 \%){ }^{48}$

Rituximab also plays an important role in the treatment of PTLD. In an analysis of the use of rituximab for the treatment of 58 patients who developed B cell PTLD following solid organ or stem cell transplant, CR occurred in $61 \%$ of patients. At a median follow-up of 61 months, OS was $46 \%{ }^{49}$ Although the FDA has not issued a specific approval for this purpose, rituximab has become an important component in the treatment of B cell PTLD, alongside other treatments for PTLD, including the withdrawal of immunosuppression, chemotherapeutic regimens, antiviral therapies, and, more recently, histone deacetylase (HDAC) inhibitors (in T cell-related PTLD). ${ }^{50-56}$

In the MCL setting, rituximab has been used in combination with the Bruton's tyrosine kinase (BTK) inhibitor ibrutinib. A phase II study of 50 patients with R/R MCL (NCT01880567) reported favorable safety profiles with $88 \%$ (95\% CI $75.7 \%$ to $95.5 \%$ ) of patients achieving an objective response at a median follow-up of 16.5 months. ${ }^{57}$ Rituximab has also been incorporated into first-line regimens with chemotherapy for MCL. In a study of 638 patients treated with a variety of chemotherapy regimens, 2-year OS was $63 \%$ and $52 \%$, respectively, for patients treated with rituximab+chemotherapy versus chemotherapy alone $(p<0.001){ }^{59}$ Another chemoimmunotherapy regimen involving rituximab has also been examined for the first-line treatment of MCL: bortezomib, rituximab, cyclophosphamide, doxorubicin, and prednisone (VR-CAP). During the clinical trial NCT00722137, 487 patients randomly received either R-CHOP or VR-CAP. Patients treated with VR-CAP experienced higher median PFS of 24.7 months (95\% CI 19.8 to 31.8 ) versus 14.4 months (95\% CI 12.0 to 16.9 ; HR $=0.63 ; 95 \%$ CI 0.50 to 0.79 ; $\mathrm{p}<0.001) .{ }^{60}$ Rituximab has also been used as a maintenance therapy in patients who have received autoSCT for MCL. During a clinical trial (NCT00921414) including 257 patients who received either maintenance rituximab or observation following autoSCT, the 4-year PFS rate was $83 \%$ (95\% CI $73 \%$ to $88 \%$ ) versus $64 \%$ (95\% CI $55 \%$ to $73 \%$ ) for rituximab versus observation, respectively (HR $0.40 ; 95 \%$ CI 0.23 to $0.68 ; \mathrm{p}<0.001$ ). The OS at 4 years was also significantly higher for patients treated with rituximab, at $89 \%$ (95\% CI $81 \%$ to $94 \%)$ compared with $80 \%$ (95\% CI $72 \%$ to $88 \%$; HR 0.50 ; $95 \%$ CI 0.26 to $0.99 ; \mathrm{p}=0.04) .{ }^{61}$ 
Two rituximab biosimilars (rituximab-abbs and rituximab-pvvr) are also currently approved by the FDA. $^{62}{ }^{63}$ Biosimilars can potentially increase patient access to important immunotherapies, and are typically approved following comparative studies that demonstrate no significant clinical difference from the reference agent. ${ }^{64}{ }^{65} \mathrm{An}$ alternative formulation of rituximab, containing hyaluronidase, is also available for subcutaneous administration after a patient has received at least one dose of intravenous rituximab. ${ }^{66}$

\section{Obinutuzumab}

Obinutuzumab, another anti-CD20 $\mathrm{mAb}$, which is humanized and binds to a different epitope of CD20, is used in the treatment of FL as an alternative to rituximab. During the GADOLIN trial (NCT01059630), patients with $\mathrm{R} / \mathrm{R}$ indolent $\mathrm{B}$ cell NHL that had been previously treated with a rituximab-containing regimen were administered obinutuzumab+bendamustine or standard of care bendamustine. ${ }^{67} 68$ The majority of these patients had follicular B cell NHL. ${ }^{69}$ Patients receiving obinutuzumab during treatment also received it as maintenance therapy ${ }^{67}$ At the time of follow-up (median 21.9 months for obinutuzumab+bendamustine, 20.3 months for bendamustine), median PFS was not reached for obinutuzumab+bendamustine, and was 13.8 months for bedamustine alone (HR 0.49; $95 \%$ CI 0.35 to 0.68 ; log-rank $\mathrm{p}<0.0001) .{ }^{69}$ Based on the results of this trial, in February 2016, the FDA approved the use of obinutuzumab in combination with bendamustine (with obinutuzumab maintenance) for the treatment of $\mathrm{R} / \mathrm{R}$ FL in patients who have previously received a rituximab-containing regimen. ${ }^{70}$

In the GALLIUM trial (NCT01332968), obinutuzumab was investigated for the first-line treatment of FL in comparison to rituximab. Patients received a chemotherapy regimen (CHOP, CVP, or bendamustine) in combination with obinutuzumab or rituximab. ${ }^{71}$ At 3 years maintenance with the assigned antibody, patients who received obinutuzumab exhibited a higher estimated rate of PFS, at $80.0 \%$ versus $73.3 \%$ (HR $0.66 ; 95 \%$ CI 0.51 to $0.85 ; \mathrm{p}=0.001){ }^{72}$ The FDA approved the use of obinutuzumab in combination with chemotherapy (followed by obinutuzumab maintenance) for the first-line treatment of bulky stage II, stage III, and stage IV FL in November $2017 .^{70}$ Notably, however, the GALLIUM trial results did not demonstrate statistically significant differences in OS at 3 years for obinutuzumab compared with rituximab ( $94.0 \%$ vs $92.1 \%$; HR 0.75 ; $95 \%$ CI 0.49 to 1.17 ; $\mathrm{p}=0.21$ ), despite reported benefits for $\mathrm{PFS}^{72}$ Obinutuzumab was also investigated as a first-line therapy for DLBCL, in combination with cyclophosphamide, doxorubicin, vincristine, and prednisone (G-CHOP), in the GOYA trial (NCT01287741). ${ }^{73}$ However, when compared with standard of care R-CHOP, G-CHOP did not significantly improve PFS. ${ }^{74}$
Ibritumomab tiuxetan

Ibritumomab tiuxetan (IT) is an anti-CD20 antibody, conjugated to the radioisotope ${ }^{90} \mathrm{Y}$. IT was evaluated for the treatment of patients with $\mathrm{R} / \mathrm{R}$, low grade or follicular B cell NHL in three clinical trials, IDEC 106-04, IDEC 106-05, and IDEC 106-06. ${ }^{75}$ In the single-arm IDEC 106-05, the ORR for patients with R/R B cell NHL was $89 \%(95 \%$ CI $70 \%$ to $97 \%) .{ }^{76}$ In IDEC $106-04$, IT was compared with rituximab in the treatment of R/R B cell NHL. The ORR was significantly higher in patients receiving IT, at $83 \%$ versus $55 \%(p<0.001) .{ }^{77}$ In IDEC 106-06, IT was used as a therapy for patients with R/R B cell NHL who had previously received rituximab. The ORR in this study was $74 \% .{ }^{78}$ These data were the basis for FDA approval of the treatment of R/R low-grade or follicular B cell NHL with IT in February 2002. ${ }^{79}$

IT has also been approved as a consolidation therapy for FL. In the trial NCT00185393, patients achieving partial response (PR) or CR following first-line chemotherapy were administered either IT or no consolidation therapy. ${ }^{80}$ The median PFS was significantly higher in the IT arm, at 36.5 months versus 13.3 months in the control arm (HR 0.47; 95\% CI 0.36 to $0.61 ; \mathrm{p}<0.0001$ ) ${ }^{81}$ Based on the results of this trial, in September 2009, the FDA approved the use of IT as consolidation for patients with FL who achieve PR or CR following chemotherapy. ${ }^{79}$ Tostitumomab, another anti-CD20 antibody conjugated to ${ }^{131} \mathrm{I}$, received FDA approval for the treatment of $\mathrm{R} / \mathrm{R}$ FL in June 2003; however, tositumomab is no longer manufactured or sold. ${ }^{82}$

\section{Brentuximab vedotin}

In addition to approvals in the cHL setting, BV has also been investigated and approved for the treatment of some subsets of T cell lymphomas (TCL). In the single-arm study NCT00866047, BV was evaluated as a therapy for R/R systemic anaplastic large cell lymphoma (sALCL), a type of peripheral TCL. ${ }^{83}$ At 5-year follow-up, the median PFS was 20 months, the OS rate was $60 \%(95 \%$ CI $47 \%$ to $73 \%$ ), and the ORR was $86 \%$ (95\% CI $74.6 \%$ to $93.9 \%$ ). ${ }^{84}$ In August 2011, the FDA approved the use of BV for the treatment of R/R sALCL after the failure of at least one multi-agent chemotherapy regimen. ${ }^{20}$

In the ECHELON-2 trial (NCT01777152), patients with CD30+, peripheral $\mathrm{T}$ cell lymphoma (PTCL) received CHOP chemotherapy or BV with cyclophosphamide, doxorubicin, prednisone $(\mathrm{A}+\mathrm{CHP})$ as first-line therapy. ${ }^{85}$ Treatment with A+CHP was associated with significantly increased median PFS of 48.2 months versus 20.8 months (HR $0.71 ; 95 \%$ CI 0.53 to $0.94 ; \log$-rank $\mathrm{p}=0.011) .{ }^{86}$ These data were the basis of FDA approval of $\mathrm{BV}$ in combination with CHP for the first-line treatment of CD30+ PTCL, including sALCL, angioimmunoblastic TCL, and PTCL otherwise not specified, in November $2018 .^{20}$

$\mathrm{BV}$ has also been approved for the treatment of two subtypes of cutaneous TCL, mycosis fungoides (MF) and primary cutaneous anaplastic large cell lymphoma (pcALCL). The ALCANZA trial (NCT01578499) 
compared BV to chemotherapy with methotrexate or bexarotene in patients with $\mathrm{R} / \mathrm{R}$ MF or pcALCL. ${ }^{87}$ The ORR in patients receiving BV was significantly higher, at $67 \%$ compared with $20 \%(\mathrm{p}<0.0001) .{ }^{86}$ Median PFS was also higher with $\mathrm{BV}$ treatment, at 16.7 months versus 3.5 months (HR 0.27; 95\% CI 0.169 to $0.430 ; \mathrm{p}<0.0001$ ) ${ }^{86} \mathrm{In}$ November 2017, the FDA approved the use of BV for the treatment of R/R CD30+ MF and pcALCL. ${ }^{20}$

In addition to TCL, BV has been examined as a therapy for CD30+ B cell lymphomas (although the FDA has not approved BV for this purpose). A phase II trial (NCT01421667) examined BV monotherapy for patients with $R / R$ DLBCL $(n=48)$. All responding patients had quantifiable CD30 expression, although the level of CD30 expression did not correlate with response. The ORR was $44 \%$ (95\% CI $27.8 \%$ to $60.4 \%$ ), and median PFS was 4 months. ${ }^{88}$ A small number of patients $(n=9)$ have been treated with BV for CD30+ PTLD. A systematic review that pooled outcomes from BV-treated patients with CD30+ PTLD $(n=9)$ across clinical trials and case studies found that results were mostly positive, with $56 \%(\mathrm{n}=5)$ of patients experiencing complete remission. ${ }^{89}$

\section{Polatuzumab vedotin-piiq}

Polatuzumab vedotin-piiq is an ADC targeted to CD79b. Study GO29365 (NCT02257567) compared polatuzumab vedotin-piiq with bendamustine+rituximab (BR) to $\mathrm{BR}$ alone in patients with R/R DLBCL or FL. ${ }^{90}$ In patients with DLBCL, those treated with polatuzumab vedotin-piiq exhibited significantly higher median PFS, at 9.5 months versus 3.7 months (HR 0.37; $95 \%$ CI 0.21 to 0.66 ; $\mathrm{p}<0.001$ ) ${ }^{91}$ The ORR was also significantly increased, at $45.0 \%$ versus $17.5 \%{ }^{91}$ The FDA approved the use of polatuzumab vedotin-piiq in combination with BR for the treatment of R/R DLBCL after at least two prior therapies in June 2019. ${ }^{92}$

\section{Mogamulizumab-kpkc}

Mogamulizumab-kpkc is an mAb targeted to CC chemokine receptor 4 (CCR4). Mogamulizumab has been evaluated for the treatment of two types of cutaneous TCL: MF and Sézary syndrome (SS). During the MAVORIC trial (NCT01728805), patients with $\mathrm{R} / \mathrm{R}$ cutaneous TCL received mogamulizumab or vorinostat. ${ }^{93}$ The median PFS was 7.7 months for mogamulizumab and 3.1 months for vorinostat (HR 0.53; 95\% CI 0.41 to 0.69 ; log-rank $\mathrm{p}<0.0001$ ), and ORR for each group was $23 \%$ and $4 \%$, respectively $(\mathrm{p}<0.00001) .{ }^{94}$ Based on this trial, in August 2018 the FDA approved mogamulizumab for the treatment of R/R MF or SS after at least one prior systemic therapy. ${ }^{95}$

\section{Pembrolizumab}

Pembrolizumab has been approved for the treatment of $\mathrm{R} / \mathrm{R}$ PMBCL in patients who have received two or more prior lines of therapy, based on the KEYNOTE- 170 trial (NCT02576990), which observed an ORR of $45 \%(95 \%$ CI $32 \%$ to $60 \%$ ), median PFS of 5.5 months (95\% CI 2.8 months to 12.1 months), and OS at 1-year follow-up estimated at $58 \% .^{96}{ }^{97}$ The trial formed the basis for FDA approval in June 2018. ${ }^{33}$

\section{Lenalidomide}

Lenalidomide, an IMiD, has been investigated and approved for a few subtypes of NHL, namely MCL, FL, and MZL. In the single-arm EMERGE trial (NCT00737529), patients with $\mathrm{R} / \mathrm{R}$ MCL were administered lenalidomide. ${ }^{98}$ The ORR of this treatment was $30 \%$, and the median PFS was 4.0 months (95\% CI 3.7 to 7.2 ) ${ }^{99}$ On the basis of data from this trial, the FDA approved lenalidomide for the treatment of patients with $\mathrm{R} / \mathrm{R}$ MCL who had received two or more prior therapies (one of which was bortezomib) in June 2013. ${ }^{100}$

In addition to being used as a monotherapy in the treatment of MCL, lenalidomide is commonly administered in combination with rituximab for the treatment of FL and MZL. In the AUGMENT trial (NCT01938001), patients with MZL or FL (grade 1-3a) were administered lenalidomide+rituximab or rituximab+placebo. ${ }^{101}$ Patients receiving lenalidomide+rituximab exhibited significantly increased median PFS, at 39.4 months versus 14.1 months (HR $0.46 ; 95 \%$ CI 0.34 to 0.62 ; $\mathrm{p}<0.0001)$. The ORR was also significantly increased in the lenalidomide arm, at $78 \%$ versus $53 \%(\mathrm{p}<0.0001) .{ }^{102}$ In the MAGNIFY trial (NCT01996865), patients with R/R FL (grade 1-3b or transformed), MZL, or MCL were administered lenalidomide+rituximab, with either rituximab or lenalidomide+rituximab (R2) administered as maintenance therapy afterward. ${ }^{103}$ While a comparison between the rituximab and $\mathrm{R} 2$ arms has not yet been published, the ORR in patients with MZL was $65 \%$, and the ORR in patients with $\mathrm{FL}$ was $74 \%$ for patients treated with R2 maintenance. ${ }^{104}$ Based on data from MAGNIFY and AUGMENT, in May 2019 the FDA approved the use of lenalidomide+rituximab for the treatment of R/R FL and MZL. ${ }^{100}$ Lenalidomide was also tested as part of a first-line therapy regimen for FL (grade 1-3a) in combination with rituximab as part of the RELEVANCE trial (NCT01476787 and NCT01650701). ${ }^{105}{ }^{106}$ In comparison between the R2 regimen and a selection of rituximab-containing chemoimmunotherapy regimens, rates of ORR, PFS, and OS were similar and did not show a clear advantage for either treatment arm. However, the safety profiles of the two treatment arms were different, with R2 resulting in a higher rate of grade $\geq 3$ cutaneous reactions and rituximab+chemotherapy resulting in a higher rate of grade $\geq 3$ neutropenia and febrile neutropenia. ${ }^{107}$

Lenalidomide has also been investigated as a treatment for DLBCL. Lenalidomide has resulted in similar efficacy to investigator's choice therapies, as in the phase II/III DLC-001 trial (NCT01197560). ${ }^{108}$ While lenalidomide did not demonstrate a clear OS advantage over other therapies as a single agent, it is sometimes used clinically in the treatment of DLBCL as an alternative with a different toxicity profile. 


\section{Axicabtagene ciloleucel}

At the time of manuscript preparation, three CAR $\mathrm{T}$ cell therapies have been approved by the FDA for the treatment of patients with lymphoma. All target cells expressing CD19, but differ in the costimulatory and hinge domains used in the CAR constructs. The single-arm ZUMA-1 trial (NCT02348216) of axicabtagene ciloleucel reported an ORR of $83 \%$, a median PFS of 5.9 months (95\% CI 3.3 to 15.0$)$, and a DOR of 11.1 months $(95 \%$ CI 4.2 to not estimable) in patients with large B cell lymphomas. At a median follow-up of 27.1 months, 39\% of patients exhibited ongoing remission and median OS was not reached. ${ }^{109110}$ Based on this study, in October 2017, the FDA granted approval to axicabtagene ciloleucel for the treatment of $\mathrm{R} / \mathrm{R}$ large $\mathrm{B}$ cell lymphomas (including DLBCL, PMBCL, high-grade B cell lymphoma, and transformed FL) after two or more prior lines of systemic therapy. ${ }^{111}$

\section{Tisagenlecleucel}

Another CD19-targeting CAR T cell therapy, tisagenlecleucel, is also approved for the treatment of $\mathrm{R} / \mathrm{R}$ large $\mathrm{B}$ cell lymphomas. In the single-arm, phase II JULIET trial (NCT02445248) for R/R DLBCL and transformed FL, tisagenlecleucel therapy resulted in an ORR of $52 \%$ (95\% CI $41 \%$ to $62 \%)$. At the data cut-off, the median DOR had not yet been reached, the median OS was 12 months (95\% CI 7 to not reached), and the median PFS had not been reached. ${ }^{112}$ In May 2018, the FDA approved the use of tisagenlecleucel for the treatment of $\mathrm{R} / \mathrm{R}$ large $\mathrm{B}$ cell lymphomas after two or more prior lines of systemic therapy. ${ }^{113}$

\section{Brexucabtagene autoleucel}

In July 2020, the FDA approved brexucabtagene autoleucel (formerly KTE-X19), an anti-CD19 CAR T cell therapy, for the treatment of R/R MCL. ${ }^{114}$ This approval was based on the phase II, open-label ZUMA-2 trial (NCT02601313). ${ }^{115}$ In this trial, 60 patients in the primary efficacy analysis with $\mathrm{R} / \mathrm{R}$ MCL received brexucabtagene autoleucel, and exhibited an ORR of $93 \%$ (95\% CI $84 \%$ to $98 \%$ ) and a CR rate of $67 \%$ (95\% CI $53 \%$ to $78 \%)$. At 12 months, the estimated OS and PFS were $83 \%$ and $61 \%$, respectively. ${ }^{116}$

\section{Tafasitamab-cxix}

During the L-MIND trial (NCT02399085), a phase II, open-label trial, 80 patients received tafasitamab-cxix (an anti-CD19 mAb) with lenalidomide for the treatment of R/R DLBCL. ${ }^{117}$ The ORR among these patients was $60 \%$ (95\% CI $48 \%$ to $71 \%$ ), the median DOR was 21.7 months (95\% CI 21.7 to not reached), the median PFS was 12.1 months (95\% CI 5.7 to not reached), and the median OS was not reached at a median follow-up of 19.6 months. ${ }^{118}$ On the basis of data from L-MIND, the FDA approved tafasitamab-cxix+lenalidomide for the treatment of $R / R$ DLBCL in patients who are not eligible for autoSCT. ${ }^{119}$
Epstein-Barr virus-directed T lymphocytes

It is hypothesized that PTLD is often linked to Epstein-Barr virus $(\mathrm{EBV})$ infection or reactivation, and $\mathrm{BV}$ represents a potential treatment option for the resulting CD30+ PTLD (as discussed earlier). A recent case study demonstrated the successful combination of BV and EBV-directed allogeneic $\mathrm{T}$ lymphocytes to treat CD30+, EBV-associated PTLD, achieving a lasting CR. ${ }^{120}$ While EBV-directed T lymphocytes have seen clinical use in the treatment of PTLD, no FDA approvals exist for these cellular therapies at the time of publication.

\section{Panel recommendations}

Diffuse large B cell lymphoma

- There was consensus that the first-line regimen for newly diagnosed DLBCL in adult patients should be R-CHOP.

- For pediatric patients with newly diagnosed DLBCL, there was consensus that first-line treatment should consist of rituximab with French-American-British (FAB) backbone chemotherapy.

- For the second-line therapy of DLBCL, there was consensus that transplant-eligible patients should receive a chemoimmunotherapy regimen that includes rituximab (such as rituximab+ICE (R-ICE) or rituximab+dexamethsone+cytarabine+cisplatin (R-DHAP) ), followed by autoSCT consolidation if CR is achieved.

- In transplant-eligible patients who receive salvage therapy and exhibit PR, the panel did not reach consensus on a preferred consolidation regimen. Options include anti-CD19 CAR T cell therapy or autoSCT.

- For second-line therapy of DLBCL in patients who are transplant-ineligible, the panel did not reach consensus on a salvage chemotherapy or immunotherapy regimen. Treatment options include lenalidomide, lenalidomide+tafasitamab-cxix, polatuzumab vedotin-piiq+BR or an appropriate salvage chemoimmunotherapy regimen (including R-GemOx or R-GDP).

- There was consensus that the third-line treatment for DLBCL in fit patients should be anti-CD19 CAR T cell therapy (axicabtagene ciloleucel or tisagenlecleucel).

- There was consensus that patients who are ineligible for third-line anti-CD19 CAR T cell therapy should instead receive polatuzumab vedotin-piiq+BR.

\section{Mantle cell lymphoma}

- The panel did not reach consensus on first-line treatment for patients with MCL who are eligible for transplant. Options include chemoimmunotherapy with autoSCT or chemoimmunotherapy alone. The standard of care for first-line MCL treatment includes an anti-CD20 mAb as part of the chemoimmunotherapy regimen.

- Patients who receive autoSCT for MCL should also receive rituximab maintenance. 
- For transplant-ineligible patients with MCL, there was consensus that first-line treatment should consist of an appropriate chemoimmunotherapy regimen with rituximab as maintenance therapy.

- The panel did not reach consensus on second-line or later lines of treatment for patients with MCL. Treatment options include brexucabtagene autoleucel, proteasome inhibitors, BTK inhibitors, BTK inhibitors+rituximab, or lenalidomide+rituximab.

\section{Follicular lymphoma}

- The panel did not reach consensus on a preferred treatment for patients with low tumor burden FL (once treatment is indicated). Treatment options include rituximab monotherapy, lenalidomide+rituximab, or chemoimmunotherapy (eg, R-CHOP or BR).

- In patients with high tumor burden FL, there was consensus that first-line treatment should consist of an appropriate chemoimmunotherapy regimen (eg, $\mathrm{R}-\mathrm{CHOP}$ or BR).

- There was consensus that second-line (or later) treatment regimens for patients with FL will vary, and should be decided on a case-by-case basis using factors that include prior therapies, time of relapse, tumor bulk, age, and comorbidity status. Ibritumomab tiuxetan may be used in this context, if deemed appropriate.

- There was consensus that when anti-CD20 antibody therapy is indicated, rituximab should be used over obinutuzumab when possible, since obinutuzumab has not demonstrated an OS benefit in comparison to rituximab.

- In patients who have been treated with rituximab, if relapse occurs less than 6 months after the last dose of rituximab, there was consensus that obinutuzumab should be used (if anti-CD20 antibody therapy is indicated). If relapse occurs more than 6 months after the last dose of rituximab, there was consensus that rituximab should be administered again (if anti-CD20 antibody therapy is indicated).

\section{Marginal zone lymphoma}

- There was consensus that first-line treatment of advanced stage, low tumor burden MZL should consist of rituximab monotherapy.

- There was consensus that first-line treatment of advanced stage, high tumor burden MZL should consist of an appropriate chemoimmunotherapy regimen.

- There was consensus that second-line (or later) treatment regimens for patients with MZL will vary, and should be decided on a case-by-case basis using factors that include prior therapies, time of relapse, tumor bulk, age, and comorbidity status.

\section{Primary mediastinal B cell lymphoma}

- There was consensus that first-line treatment of PMBCL should consist of DA-R-EPOCH.
- There was consensus that second-line treatment of PMBCL should be identical to the recommendations listed for DLBCL (see earlier).

- The panel did not reach consensus on a specific treatment regimen for the third-line treatment of PMBCL. Treatment options include axicabtagene ciloleucel, $\mathrm{BV}+$ pembrolizumab, or appropriate salvage chemotherapy regimens.

\section{Burkitt's lymphoma}

- There was consensus that first-line treatment of BL in children, adolescents, and young adults should consist of a rituximab-containing chemoimmunotherapy regimen, either rituximab+FAB chemotherapy backbone or rituximab+Berlin-Frankfurt-Münster (BFM) chemotherapy backbone.

- There was consensus that second-line treatment of BL in children, adolescents, and young adults should consist of a rituximab-containing chemoimmunotherapy regimen (eg, R-ICE or rituximab, cytarabine, etoposide (R-CYVE)).

- There was consensus that children, adolescents, and young adults who achieve PR or CR should receive stem cell transplantation as consolidation therapy (if eligible). In the event of prior bone marrow involvement, allogeneic stem cell transplant (alloSCT) is indicated, whereas autoSCT is recommended in all other cases.

- There was consensus that first-line treatment of BL in adults should consist of a rituximab-containing chemoimmunotherapy backbone. Options include rituximab+Lymphome Malins de Burkitt (R-LMB), rituximab+cyclophosphamide+doxorubicin +methotrexate / ifosfamide+etoposide+cytarabine (R-CODOXM/IVAC), DA-R-EPOCH, rituximab+ German Multicenter Study Group for Adult Acute Lymphoblastic Leukemia Protocol (R-GMALL), and rituximab+cyclophosphamide+vincristine+doxorubicin+dexamethasone alternating with rituxima$\mathrm{b}+$ methotrexate+cytarabine (R-HyperCVAD).

- There was consensus that second-line treatment of BL in adults should consist of rituximab-containing chemoimmunotherapy regimens similar to those recommended for the first-line treatment of BL, with consolidation being identical to recommendations for consolidation in patients with DLBCL.

\section{T cell lymphoma}

- The panel did not reach consensus on a single recommended regimen for the first-line treatment of CD30+ PTCL. Treatment options include BV with cyclophosphamide+doxorubicin+prednisone (CHP), chemotherapy alone, or chemotherapy+autoSCT (if eligible).

- There was consensus that first-line treatment for CD30-negative PTCL should consist of an appropriate chemotherapy regimen+autoSCT. 
- The panel did not reach consensus on a single recommended regimen for second-line treatment of PTCL in patients eligible for stem cell transplant. Treatment options include chemotherapy+autoSCT, chemotherapy+alloSCT, or HDAC inhibitors.

- There was consensus that second-line treatment for CD30+ PTCL in patients ineligible for stem cell transplant should consist of BV, up to 16 total doses.

- There was consensus that second-line treatment for CD30-negative PTCL should consist of HDAC inhibitors.

- Patients with anaplastic large cell lymphoma that is anaplastic lymphoma kinase-positive (ALK+) should not receive autoSCT.

- The panel did not reach consensus on a single recommended regimen for the first-line treatment of cutaneous TCL. Treatment options include BV, HDAC inhibitors, and an appropriate chemotherapy regimen.

- The panel did not reach consensus on a single recommended regimen for the second-line treatment of cutaneous TCL. Treatment options include HDAC inhibitors, an appropriate chemotherapy regimen (such as pralatrexate), and BV.

\section{Post-transplant lymphoproliferative disorder}

- The panel did not reach consensus on a preferred regimen for the treatment of B cell PTLD. Treatment options include the withdrawal of immunosuppression, rituximab, appropriate chemoimmunotherapy regimens, and antiviral agents.

- The panel did not reach consensus on a preferred regimen for the treatment of T cell PTLD. Treatment options include the withdrawal of immunosuppression, appropriate chemotherapy regimens, HDAC inhibitors, and antiviral agents.

\section{Immunotherapies in development for NHL}

A number of late-stage clinical trials are currently in progress for NHL (listed in table 2). Notably, new CAR $\mathrm{T}$ cell therapies including lisocabtagene maraleucel (a CAR $\mathrm{T}$ cell therapy targeted to CD19, being examined for the treatment of R/R B cell NHL) are currently in development.

\section{CHRONIC LYMPHOCYTIC LEUKEMIA}

FDA-approved immunotherapies for the treatment of chronic lymphocytic leukemia (CLL) are discussed in this section, ordered by history of clinical use.

\section{Available agents and indications \\ Rituximab}

Rituximab has been approved for the treatment of CLL in both first-line and $\mathrm{R} / \mathrm{R}$ settings, in combination with fludarabine and cyclophosphamide (FC). In the phase III CLL-8 study (NCT00281918), patients received either rituximab+FCor FC for previously untreated CLL. ${ }^{121}$
Patients receiving rituximab+FC in this study exhibited significantly higher PFS at 5-year follow-up, 56.8 months compared with 32.9 months (HR 0.59 ; $95 \%$ CI 0.50 to $0.69 ; \mathrm{p}<0.001)$. The ORR with rituximab+FC was also significantly higher, at $90 \%$ versus $80 \%(\mathrm{p}<0.001) .{ }^{122}$ In the REACH trial (NCT00090051), patients with R/R CLL received rituximab+FCor FC alone. ${ }^{123}$ Patients treated with rituximab+FC had significantly higher median PFS of 27.0 months versus 21.9 months (HR 0.76 ; 95\% CI 0.60 to $0.96 ; \mathrm{p}=0.0218) .{ }^{124}$ The ORR was also significantly higher in rituximab-treated patients $(61 \%$ vs $49 \%$; $\mathrm{p}=0.0048) .{ }^{124}$ Based on these results, in February 2010, the FDA approved the use of rituximab in combination with FC to treat CLL, with no restrictions related to prior therapy. ${ }^{37}$

Another combination regimen including the BTK inhibitor ibrutinib with rituximab for the first-line treatment of CLL was approved by the FDA in April, 2020. ${ }^{125}$ During the phase III E1912 trial (NCT02048813), patients received first-line ibrutinib+rituximab or rituximab+fludarabine+cyclophosphamide. ${ }^{126}$ The median PFS was not reached for either group, but the percentage of progression-free patients was higher for those treated with ibrutinib at 3 years $(89.4 \%$ vs $72.9 \%$; HR 0.35 ; $95 \%$ CI 0.22 to $0.58 ; \mathrm{p}<0.001)$. OS was also significantly higher at 3 years for patients treated with ibrutinib $(98.8 \%$ vs 91.5\%; HR 0.17 ; $95 \%$ CI 0.05 to $0.54 ; \mathrm{p}<0.001) .{ }^{127}$

\section{Obinutuzumab}

Obinutuzumab has been evaluated in the first-line setting for CLL. In CLL11 (NCT01010061), patients received obinutuzumab+chlorambucil, rituximab+chlorambucil, or chlorambucil alone. ${ }^{28}$ Compared with chlorambucil alone, obtinutuzumab+chlorambucil treatment was associated with a significantly longer median PFS of 31.1 months versus 11.1 months (HR $0.21 ; 95 \%$ CI 0.16 to $0.28 ; \mathrm{p}<0.0001$ ) after median follow-up of 62.5 months. At a median follow-up of 59.4 months, patients treated with obinutuzumab+chlorambucilalso exhibited a clear advantage in median PFS over patients treated with rituximab+chlorambucil, at 28.9 months versus 15.7 months (HR 0.49 ; $95 \%$ CI 0.41 to 0.58 ; $\mathrm{p}<0.0001$ ). ${ }^{129}$ On the basis of data from CLL11, the FDA approved the use of obinutuzumab+chlorambucil for the first-line treatment of CLL in November 2013. ${ }^{70}$

\section{Ofatumumab}

Ofatumumab, an anti-CD20 $\mathrm{mAb}$, has been approved for the treatment of CLL as a first-line, maintenance, or salvage therapy. In the COMPLEMENT 1 trial (NCT00748189), patients with untreated CLL received chlorambucil with or without ofatumumab. ${ }^{130}$ Treatment with ofatumumab+chlorambucil resulted in a significantly higher median PFS of 22.4 months versus 13.1 months (HR 0.57; 95\% CI 0.45 to $0.72 ; \mathrm{p}<0.0001$ ), which led to FDA approval of ofatumumab+chlorambucil for the firstline treatment of CLL in April 2017. ${ }^{131} 132$ 


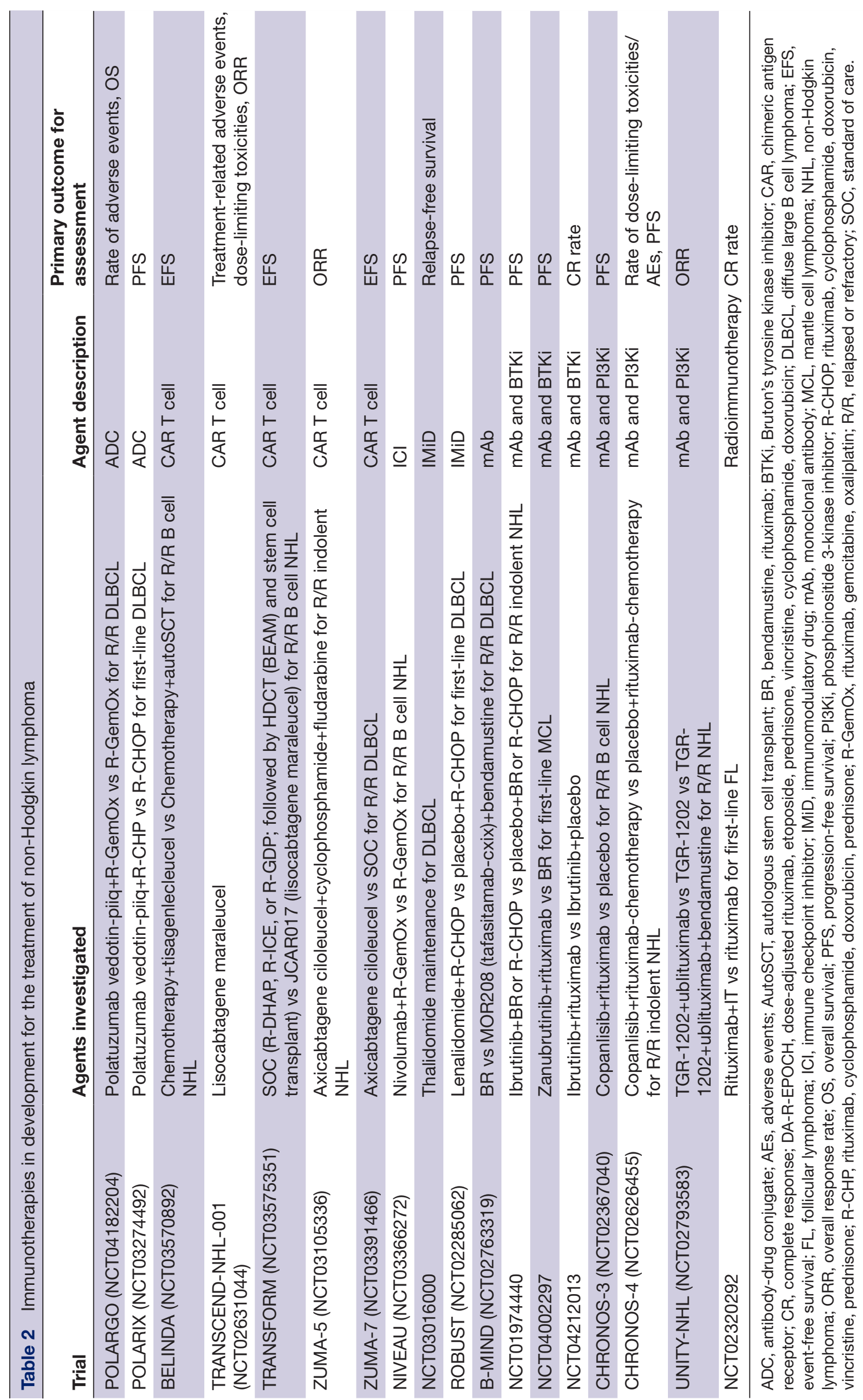


Ofatumumab also demonstrated clinical benefit as a maintenance therapy in the phase IV PROLONG trial (NCT00802737), which enrolled patients with prior response to ofatumumab. ${ }^{133}$ Patients who received ofatumumab maintenance exhibited longer PFS, with a median of 30.4 months versus 14.8 months (HR 0.55; $95 \%$ CI 0.42 to $0.72 ; \mathrm{p}<0.0001) .{ }^{134}$ In January 2016 , the FDA approved the use of ofatumumab as maintenance therapy for patients with CLL in CR or PR following at least two lines of therapy. ${ }^{132}$

In the setting of R/R CLL, ofatumumab has been the subject of multiple trials. During COMPLEMENT 2 (NCT00824265), patients with R/R CLL were administered FC with or without ofatumumab; patients treated in the ofatumumab arm had significantly longer median PFS, at 28.9 months versus 18.8 months (HR $0.67 ; 95 \%$ CI 0.51 to $0.88 ; \mathrm{p}=0.0032){ }^{135} 136$ The ORR was also significantly higher in the ofatumumab treatment arm- $84 \%$ versus $68 \%(p=0.0003) .{ }^{136}$ In August 2016, the FDA approved ofatumumab+FC for the treatment of relapsed CLL. ${ }^{132}$ During the single-arm NCT00349349 trial, patients with R/R CLL who had previously received fludarabine and alemtuzumab were treated with ofatumumab monotherapy. ${ }^{137}$ The ORR was $58 \%$ (99\% CI $40 \%$ to $74 \%$ ) with median PFS of 5.7 months (95\% CI 4.5 to 8.0) ${ }^{138}$ Based on NCT00349349, the FDA approved ofatumumab for the treatment of R/R CLL in patients who have previously been treated with fludarabine and alemtuzumab in October 2009. ${ }^{132}$

Alemtuzumab

Alemtuzumab, an anti-CD52 mAb, has been approved for the treatment of B cell CLL as a monotherapy. In the phase III CAM307 trial (NCT00046683), alemtuzumab was compared with chlorambucil as first-line therapy for CLL. ${ }^{139}$ Patients receiving alemtuzumab exhibited prolonged PFS, at a median of 14.6 months versus 11.7 months (HR 0.58 ; 95\% CI 0.43 to 0.77 ; log-rank $\mathrm{p}=0.0001) .{ }^{140}$ Based on the results of CAM307, the FDA approved the use of alemtuzumab for the first-line treatment of CLL in September 2007, expanding the existing indication to include all B cell CLL. ${ }^{141}$

Alemtuzumab also demonstrated safety and efficacy in the treatment of R/R CLL during three single-arm studies with reported ORRs of $42 \%$ (95\% CI 23\% to $61 \%$ ), 33\%, and $31 \%{ }^{142-144}$ Based on an analysis of these studies, in May 2001 the FDA approved the use of alemtuzumab for the treatment of R/R CLL. ${ }^{141}$

\section{Panel recommendations}

- The panel did not reach consensus on preferred regimens for the first-line or second-line treatment of CLL. Options include targeted therapy (if eligible) and chemoimmunotherapy regimens, which may include rituximab, obinutuzumab, ofatumumab, and alemtuzumab.

\section{Immunotherapies in development for CLL}

Late-stage clinical trials evaluating novel agents and new combinations of immunotherapies for the treatment of CLL are listed in table 3.

\section{INTEGRATION OF HEMATOPOIETIC STEM CELL TRANSPLANT AND IMMUNOTHERAPIES}

Stem cell transplant has been and remains a mainstay treatment option with curative potential for patients with lymphoma. ${ }^{145-147}$ Indeed, one can consider alloSCT

Table 3 Immunotherapies in development for the treatment of chronic lymphocytic leukemia

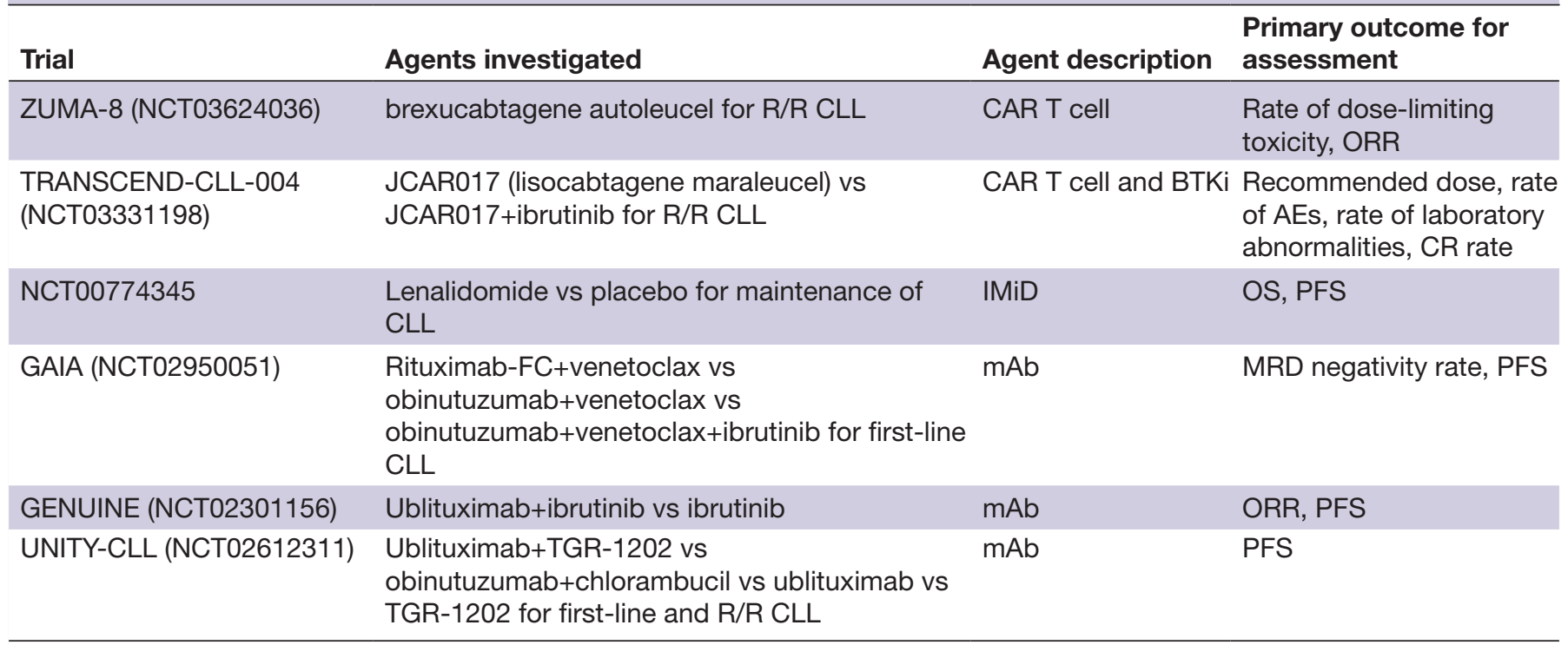

AEs, adverse events; BTKi, Bruton's tyrosine kinase inhibitor; CLL, chronic lymphocytic leukemia; CR, complete remission; FC, fludarabine, cyclophosphamide; IMiD, immunomodulatory drug; mAb, monoclonal antibody; MRD, minimal residual disease; ORR, overall response rate; OS, overall survival; PFS, progression-free survival; R/R, relapsed or refractory. 
one of the oldest and most successful forms of immunotherapy for lymphoma with the ability to generate a graft-versus-lymphoma effect. The introduction of novel immunotherapies, however, has given rise to a number of questions concerning optimal scheduling with and around stem cell transplant. There are many questions to consider, including whether to schedule immunotherapy pre-transplant or post-transplant, and whether immunotherapy may alter transplant efficacy, which have yet to be conclusively resolved in the clinic. Specifically, ICIs are a source of concern, since these therapies have the potential to induce lasting changes in the host immune system, which could conceivably increase the risk of complications following transplantation (eg, graft vs host disease $($ GVHD) ). There is also a theoretical concern that using CAR $T$ cells collected from patients after alloSCT, when they are likely to be of donor origin, could induce GVHD.

\section{Modality-specific considerations \\ Immune checkpoint inhibitors}

Both nivolumab and pembrolizumab, which are currently approved for the treatment of select lymphomas, are typically administered in contexts where patients have already undergone autoSCT. In this setting, ICIs have exhibited promising response rates and tolerable levels of toxicity. ${ }^{27}{ }^{148}$ In contrast, little data currently exists regarding the administration of ICIs prior to autoSCT for patients with lymphoma.

AlloSCT, when used in conjunction with ICI therapy, appears to carry some risk of AEs, including GVHD. In a retrospective analysis of $31 \mathrm{cHL}$ patients receiving nivolumab or pembrolizumab following alloSCT, ORR was $77 \%$ (95\% CI $58 \%$ to $90 \%$ ), but $55 \%(\mathrm{n}=17)$ of patients developed GVHD (19\% acute $(\mathrm{n}=6), 23 \%$ chronic $(\mathrm{n}=7)$, and $13 \%$ acute/chronic overlap $(\mathrm{n}=4)) .{ }^{149}$ Similarly, a retrospective analysis of 107 patients from seven studies who received ICIs prior to alloSCT exhibited an ORR of $68 \%$, but $56 \%$ of patients developed acute GVHD and 29\% developed chronic GVHD. $60 \%$ of patient deaths reported were GVHD-related. ${ }^{150}$ Another analysis of patients who received anti-PD-(L) 1 inhibitors prior to alloSCT demonstrated that patients were at higher risk of acute GVHD if time to transplant was short, and that prophylactic cyclophosphamide improved patient outcomes while reducing the risk of chronic GVHD. ${ }^{151}$ Generally, the use of ICIs in conjunction with alloSCT may result in improved response rates, but caution must be exercised due to the high likelihood of GVHD. Future studies may also identify ways to integrate these two therapeutic methods while minimizing the risk of GVHD.

\section{CAR T cell therapies}

Concerning CAR T cell therapies, confirmatory clinical trials resulting in approval of tisagenlecleucel and axicabtagene ciloleucel included patients who had received prior autologous stem cell transplant, and reported consistent efficacy across subgroups. ${ }^{112} 152$ There is ongoing debate in the field of lymphoma treatment as to the potential for CAR T cell therapy to be used in conjunction with, or to replace, traditional autoSCT. ${ }^{153} 154$

Little data exists regarding the use of CAR $\mathrm{T}$ cell therapy in conjunction with alloSCT for the treatment of lymphoma. In patients with a different hematological malignancy, B cell acute lymphoblastic leukemia, anti-CD19 CAR T cell therapies have been successfully used as a bridge therapy to enable subsequent alloSCT, with promising rates of $\mathrm{CR}$ and no reported incidence of GVHD. ${ }^{155156}$ This result may serve as a blueprint for future research in the use of alloSCT after CAR $\mathrm{T}$ cell therapies.

\section{Panel recommendations}

- There was consensus that ICI and CAR T cell therapy are both acceptable after a patient has received autoSCT. The panel did not reach consensus on the subject of whether ICIs or CAR T cell therapy should be administered prior to autoSCT.

- There was consensus that CAR T cell therapy is safe and could be considered following alloSCT, if the patient does not have active GVHD or require immunosuppression. Caution should also be exercised for patients with a history of severe GVHD.

- The panel did not reach consensus on the subject of whether ICIs should be considered contraindicated before or after alloSCT.

\section{RECOGNITION AND MANAGEMENT OF IRAES}

Management of AEs that may arise during administration of immunotherapies is an important and ongoing area of research. Additionally, the administration of CAR T cell therapies carries the risk of cytokine release syndrome (CRS) and/or neurotoxicities, both of which can be fatal if not properly identified and managed. Potentially lifethreatening toxicities are noted through a 'black box warning' on FDA labeling information. A summary of black box warnings for immunotherapies discussed in this document can be found in table 4 .

\section{CRS and CNS events}

CRS and CNS events are of primary concern during CAR $\mathrm{T}$ cell therapy, although they have also been reported after treatment with other forms of immunotherapy, such as nivolumab and rituximab. ${ }^{157-160}$ One hallmark of CRS is profoundly increased interleukin (IL)-6 serum concentration, and treatment with the IL-6 receptor antagonist tocilizumab has been demonstrated to be effective in mitigating this AE. ${ }^{161}$ Indeed, tocilizumab was approved by the FDA to manage CRS concurrently with the initial approval of tisagenlecleucel. ${ }^{162}$ Corticosteroids are also frequently used together with tocilizumab to manage CRS, as well as alone, in refractory cases. ${ }^{155} 163$ Importantly, tocilizumab does not alleviate ICANS. Currently, corticosteroids are commonly administered for ICANS, 
Table 4 Food and Drug Administration black box warnings for lymphoma immunotherapies

\begin{tabular}{|c|c|}
\hline Therapy & Warning due to \\
\hline Alemtuzumab & $\begin{array}{l}\text { Autoimmune conditions } \\
\text { (immune thrombocytopenia, } \\
\text { anti-glomerular basement } \\
\text { membrane disease) } \\
\text { Severe infusion reactions } \\
\text { Anaphylaxis } \\
\text { Cancer (thyroid, melanoma, } \\
\text { lymphoproliferative disorders) } \\
\text { Infections }\end{array}$ \\
\hline Axicabtagene ciloleucel & $\begin{array}{l}\text { CRS } \\
\text { ICANS } \\
\text { Do not administer to patients } \\
\text { with active infection or } \\
\text { inflammatory disorders }\end{array}$ \\
\hline $\begin{array}{l}\text { Brexucabtagene } \\
\text { autoleucel }\end{array}$ & $\begin{array}{l}\text { CRS } \\
\text { ICANS } \\
\text { Do not administer to patients } \\
\text { with active infection or } \\
\text { inflammatory disorders }\end{array}$ \\
\hline Brentuximab vedotin & $>\mathrm{PML}$ \\
\hline Ibritumomab tiuxetan & $\begin{array}{l}\text { Severe infusion reactions } \\
\text { Severe cytopenia } \\
\text { Severe cutaneous/ } \\
\text { mucocutaneous reactions } \\
\text { Do not administer if patient } \\
\text { exhibits altered biodistribution }\end{array}$ \\
\hline Lenalidomide & $\begin{array}{l}\text { Embryo-fetal toxicity } \\
\text { (pregnancy must be excluded } \\
\text { prior to treatment) } \\
\text { Significant neutropenia, } \\
\text { thrombocytopenia }\end{array}$ \\
\hline Obinutuzumab & $\begin{array}{l}\text { - Hepatitis B virus reactivation } \\
\text { PML }\end{array}$ \\
\hline $\begin{array}{l}\text { Rituximab (and } \\
\text { biosimilars) }\end{array}$ & $\begin{array}{l}\text { Severe infusion reactions } \\
\text { TLS } \\
\text { Severe mucocutaneous } \\
\text { reactions } \\
\text { PML } \\
\text { Pepatitis B virus reactivation }\end{array}$ \\
\hline Tisagenlecleucel & $\begin{array}{l}\text { CRS } \\
\text { ICANS } \\
\text { Do not administer to patients } \\
\text { with active infection or } \\
\text { inflammatory disorders }\end{array}$ \\
\hline
\end{tabular}

CNS, central nervous system; CRS, cytokine release syndrome; PML, progressive multifocal leukoencephalopathy; TLS, tumor lysis syndrome.

and how to best manage neurological toxicities remains an active and important area of study. ${ }^{164-166}$

\section{Infusion reactions}

Infusion reactions with immunotherapies include both typical hypersensitivity (allergic, immune-mediated) and non-allergic reactions. ${ }^{167168}$ Despite some similarities in symptoms, infusion reactions should not be confused with tumor-lysis syndrome (TLS), which is a distinct AE resulting from the widespread lysis of tumor cells following administration of therapy (whereas infusion reactions represent a response to the therapy itself). Allergic reactions are relatively uncommon, but are potentially serious and can lead to anaphylaxis. ${ }^{169-172}$ Infusion reactions, by contrast, are common when mAbs are administered to patients or following autoSCT/alloSCT, and are typically short-lived. While the majority of infusion reactions are mild, a small percentage are severe and can be fatal. ${ }^{173} 174$ In the case of mAbs, infusion reactions are most common on first infusion, with frequency decreasing during subsequent infusions. ${ }^{170175}$ Of the therapies discussed in this guideline, rituximab carries the greatest risk of infusion reactions, with $77 \%$ of patients developing a reaction on first infusion. ${ }^{37}$ In the case of CAR $\mathrm{T}$ cell infusion, one analysis estimated that infusion reactions occurred in $12.6 \%$ of patients who received ex vivo manipulated $\mathrm{T}$ cells (including CAR T cells), and were typically mild. ${ }^{176}$ More detailed guidance on the management of infusion reactions may be found in published guidelines. ${ }^{177}$

\section{Tumor-lysis syndrome}

TLS, occurring due to a sudden and massive release of metabolites after widespread lysis of tumor cells, is also a potential side effect of immunotherapies, and the risk of TLS is especially high in patients with hematological malignancies and high disease burdens. ${ }^{178}$ A systematic review of TLS in patients with hematological malignancies determined that the incidence of TLS after treatment with immunotherapy ranged from no recorded TLS cases (ofatumumab) to as much as $10 \%$ (CAR $\mathrm{T}$ cell therapies). ${ }^{179}$ TLS can be managed through a combination of prophylactic methods such as hydration and hypouricemic agents like allopurinol, and reactive methods like dialysis. $^{180}$

\section{Immune-related adverse events}

In addition to the toxicities listed earlier, a number of irAEs, collectively termed irAEs, are associated with ICIs. These irAEs frequently resemble autoimmune reactions, and can manifest with a wide variety of symptoms affecting several distinct organ systems. ${ }^{181} 182$ The most commonly diagnosed irAEs include rash, pruritus, fatigue, diarrhea/ colitis, endocrinopathies, hepatic toxicities, and pneumonitis. ${ }^{181}$ Treatment of irAEs commonly involves temporary withdrawal of therapy (in the case of ICIs) and management of symptoms with corticosteroids. ${ }^{183}$ Severe ( $\geq$ grade 3) irAEs may necessitate permanent cessation of the immunotherapy and/or additional immunosuppressive agents. ${ }^{183}$ In contrast to toxicities arising from conventional cancer treatment modalities, toxicity from immunotherapy can occur after a significant delay, sometimes arising months, or years, after a treatment regimen has been discontinued. ${ }^{184}$ Based on currently available data, there is no direct evidence that patients with lymphoma being treated with immunotherapies are any more or 
less likely to experience AEs compared with patients with solid tumors being treated with the same agents.

More detailed discussion of ICI-associated irAEs, which have a very wide range of clinical manifestations, is beyond the scope of this manuscript. Guidance on the management of toxicity and irAEs in patients treated with ICIs may be found in SITC's Guide to Managing Immunotherapy Toxicity, or in other published guidelines. ${ }^{182} 183185186$

\section{PATIENT CONSIDERATIONS FOR IMMUNOTHERAPY IN THE TREATMENT OF LYMPHOMA}

To ensure both safety and efficacy, patient characteristics including age, history of viral infection, and immune system function must be considered when determining whether a patient with lymphoma should be a candidate for immunotherapy. For example, lymphoma can arise in both pediatric and elderly patient populations, presenting questions of tolerability and fitness. Research suggests that HIV, hepatitis $\mathrm{C}$ virus (HCV), and EBV viral infections can give rise to lymphoma, so the possibility of viral reactivation after immunotherapy is another risk, especially in the case of treatment regimens that result in the elimination of patient B cells. ${ }^{187-189}$ Additionally, immune system function and lymphocyte count must be considered prior to a decision to proceed with CAR T cell therapy or other therapies that rely on the collection of autologous T cells.

\section{Patients with viral infections}

No unique exclusion criteria exist for the treatment of patients with lymphoma with FDA-approved immunotherapies compared with approvals granted in other disease settings. The field of oncology in general, however, does often consider specific circumstances where immunotherapy administration may worsen a pre-existing condition. In particular, any form of adoptive cell therapy, including CAR T cell therapies, autoSCT, and alloSCT, may be contraindicated by the presence of active bacterial or viral infections. Concerns have also been noted regarding the possibility that CAR $\mathrm{T}$ cell therapies could impair host humoral immunity through the removal of healthy B cells and subsequent loss of, for example, antibody titers to common vaccines. An analysis of 39 adults with durable remission of $\mathrm{B}$ cell malignancies following anti-CD19 CAR $\mathrm{T}$ cell therapy noted that, while total IgG was reduced, measles-specific IgG remained similar to pre-CAR T cell infusion levels. Further, patients were evaluated to determine the number of viruses and viral epitopes to which there was a detectable antibody response. Pre- and post-CAR T cell therapy, the median numbers of viruses (10 vs 10) and the median numbers of viral epitopes (144 vs 139) were similar, suggesting that humoral immunity was not strongly affected by CAR $\mathrm{T}$ cell treatment. ${ }^{190}$ Detailed guidelines on best practices in this area are outside the scope of this manuscript, but have been published by other societies. ${ }^{191}$
Patients with HIV have historically been excluded from receiving immunotherapies due to limited information concerning potential effects on a patient's weakened immune system. Of importance, HIV is a risk factor for the development of NHL, so the incidence of lymphoma in patients with HIV is increased compared with other disease settings. ${ }^{188}$ Recent data investigating checkpoint inhibitor safety in HIV+ patients with cancer enrolled in the CITN-12 trial-including three patients with lymphoma-showed that the overall irAE profile resembled what was seen in clinical trials limited to HIVnegative patients. ${ }^{192} 193$ Additional studies of patients with HIV include the prospective DURVAST trial (NCT03094286), which included 20 patients with solid tumors and HIV treated with durvalumab, and a metaanalysis of 73 patients with HIV and advanced cancer treated with ICIs. In both of these studies, rates of AEs were similar to those seen in the general population, and no significant effects on CD4+ Tcell counts or HIV load were detected. ${ }^{194} 195$ Similarly, two retrospective studies of 23 and 16 patients with HIV and a variety of cancer types found that treatment with anti-PD-1 ICIs was welltolerated, with no significant effect on CD4+ T cell counts or HIV load, and that anti-PD-1 ICIs appeared to be efficacious despite the potential for patients with HIV+ to be immunocompromised. ${ }^{196} 197$ Additional trials specifically examining the efficacy and safety of ICIs in HIV+ patients with lymphoma are ongoing, and include AMC 095 (NCT02408861), which is recruiting patients with HIVassociated cHL or solid tumors. ${ }^{198}$ As with ICIs, patients with HIV have been commonly excluded from CAR T cell therapy trials. However, a small case series showed that axicabtagene ciloleucel treatment can induce responses in HIV+ DLBCL patients without causing significant toxicity. ${ }^{199} 200$

Rituximab has also been the subject of extensive study for the treatment of HIV+ patients with lymphoma. A pooled analysis of AIDS-Malignancy Consortium trials of R-CHOP and R-EPOCH for HIV-associated NHL found that patients $(\mathrm{n}=150)$ with $\mathrm{CD} 4+\mathrm{T}$ cell counts $\geq 50$ cells/ $\mu \mathrm{L}$ exhibited typical rates of treatment-related mortality (6\% for R-CHOP and 5\% for R-EPOCH) ${ }^{201}$ Another study of 52 patients with HIV-associated NHL found that R-CHOP was efficacious (CR rate $77 \%$ ) and did not result in large numbers of infections or AIDS-related events, although CD $4+\mathrm{T}$ cell counts of $<100$ cells $/ \mu \mathrm{L}$ were associated with treatment failure. ${ }^{202}$

Reactivation of hepatitis has been reported in patients treated with immunogenic mAbs including rituximab and BV, among others. In one example, $26.3 \%$ of HCV+ patients with NHL treated with EPOCH-R experienced viral reactivation, compared with $2.1 \%$ in uninfected patients. ${ }^{203}$ However, antiviral prophylaxis may be effective in the prevention of hepatitis reactivation during ICI therapy. During the CheckMate 040 and the KEYNOTE224 trials, which included HBV+ and HCV+ patients with hepatocellular carcinoma, anti-HBV prophylaxis was required and no viral flares were detected. ${ }^{204} 205$ 
Members of the herpesvirus family may also reactivate in patients who are latently infected. For example, a retrospective study of 46 NHL patients (all of whom were seropositive for cytomegalovirus (CMV)) observed that patients who were treated with rituximab following autoSCT were significantly more likely to experience CMV reactivation than patients who were not $(17.6 \%$ vs $0 \%$, respectively). ${ }^{206}$ Treatment with alemtuzumab may also increase the risk of CMV reactivation. A multi-hospital study of 102 patient outcomes determined that the risk of CMV reactivation following treatment with alemtuzumab was $38.9 \%$ (although this was not directly compared with patients not receiving alemtuzumab). ${ }^{207}$

Another notable virus that carries a risk of reactivation during immunotherapy is polyoma virus JC, or JC virus. JC virus exists in a latent state in brain tissue in a significant portion of the population, and viral reactivation may lead to progressive multifocal leukoencephalopathy (PML), a serious and potentially fatal disease. ${ }^{208} 209$ Due to the risk of this severe complication, a number of immunotherapies, including BV, rituximab, and obinutuzumab, have received black box warnings from the FDA (table 4) for JC virus reactivation. Fortunately, the development of PML appears to be a rare occurrence. A retrospective analysis following rituximab treatment in NHL patients found five cases of PML in 821 patients, or $0.6 \%$ of patients. ${ }^{210} \mathrm{In}$ comparison, patients with hematological malignancies as a whole develop PML at an estimated rate of $0.07 \%{ }^{211}$

\section{Patients with bacterial infections}

The presence of active bacterial infection is typically considered a contraindication to adoptive cell therapies due to potential exacerbation of infection with immunosuppressive conditioning regimens. In at least one case study, a death following CAR T cell therapy for the treatment of CLL was attributed to a cryptic infection leading to fatal sepsis, although the patient's blood cultures were negative prior to infusion. ${ }^{212}$

\section{Patients of advanced age}

The median age for diagnosis of NHL is 67 , and higher patient age is associated with poorer prognosis. ${ }^{213-215} \mathrm{~A}$ number of clinical trials have yielded data for patients of advanced age ( $\geq 65$ years), and have demonstrated that efficacy is not compromised for most forms of immunotherapy. In a subgroup analysis of cHL patient trials, ORRs following nivolumab treatment were similar between patients less than 65 years of age and older patients, but the patients greater than 65 years of age exhibited a higher rate of grade 3 or grade 4 irAEs $(37.5 \%$ in $<65,42.9 \%$ in $\geq 65) \cdot{ }^{216} \mathrm{~A}$ trial treating $\mathrm{cHL}$ patients with pembrolizumab also demonstrated similar rates of response between the younger than 65 and older than 65 cohorts. ${ }^{32}$ CAR $\mathrm{T}$ cell therapy exhibits similar response rates across age groups, with NHL patients over 65 in the ZUMA-1 clinical trial experiencing comparable outcomes to other patient groups. ${ }^{152} 217$ Despite these promising results, elderly patients are underrepresented in clinical trials of
ICI therapies, and a number of trials that have included elderly patients did not analyze age-based subgroups. ${ }^{218}$ Further research in this area is warranted, especially considering the high number of elderly patients with lymphoma.

\section{Patients with pre-existing autoimmune disorders}

Patients with autoimmune diseases have not been included in most clinical trials of ICIs. Because the irAEs associated with ICI therapy resemble some autoimmune disorders, and because ICIs function by interfering with the mechanisms that prevent autoimmunity, it was believed that these patients would be at increased risk for irAEs and for flare-ups of existing autoimmune disorders. However, the potential use of ICIs in these patients is important to study due to the efficacy of ICIs in cancer treatment. This is especially relevant to the treatment of lymphomas, since some autoimmune disorders (including Sjögren syndrome, systemic lupus erythematosus, and hemolytic anemia) are associated with an elevated risk of NHL. ${ }^{219}$

A retrospective study of 30 melanoma patients with autoimmune diseases who received ipilimumab (an antiCTLA-4 ICI) showed that $27 \%$ of patients had an exacerbation of their existing autoimmune disease, while $33 \%$ of patients experienced conventional grade $3-5$ irAEs. ${ }^{220}$ Another study of 56 patients with non-small cell lung cancer and an existing autoimmune disease found that 23\% of patients experienced exacerbation of existing autoimmunity and $38 \%$ of patients developed an irAE (26\% of irAEs were grade 3 or grade 4 ) following treatment with PD-1 inhibitor treatment. ${ }^{221}$ These results indicate that while ICIs may cause exacerbations of existing autoimmune conditions, patients treated with anti-PD(L) 1-axis ICIs do not appear to develop new irAEs more frequently than patients without autoimmune diseases. The possibility of a flare-up should be weighed based on the autoimmune disease that is present as some autoimmune disorders are more dangerous than others when active. It is important to note that because the aforementioned data on patients with autoimmune disorders was gathered from studies of patient with solid tumors, patients with lymphoma and existing autoimmune disorders may respond differently.

\section{Patients who have received solid organ transplant}

Historically, patients who have previously received solid organ transplants have been excluded from trials involving immunotherapies, owing to concerns that enhanced immune activation could lead to increased rates of transplant rejection or graft loss. However, since the clinical introduction of ICIs, a number of patients with solid organ transplants have undergone ICI therapy. In a retrospective study of 39 patients fitting these criteria, $41 \%$ experienced allograft rejection following initiation of ICI therapy. Within the group of patients experiencing rejection, 13 patients $(81 \%)$ progressed to graft loss. ${ }^{222}$ Given this result, it is clear that further research is needed on the safety and efficacy of cancer immunotherapy in 
solid organ transplant recipients, and that caution should be exercised in the use of immunotherapy within this group of patients.

\section{Panel recommendations}

- There was consensus that patients with an existing autoimmune disorder that requires immunosuppressive therapy should not receive ICIs.

- The panel did not reach consensus on the subject of whether patients with active bacterial infections should receive ICI therapy. There was consensus that patients with active bacterial infections should not receive CAR T therapy, autoSCT, or alloSCT.

- The panel did not reach consensus on the subject of whether patients with active viral infections should receive ICI therapy or autoSCT. There was consensus that patients with active viral infections should not receive CAR T therapy or alloSCT.

- Patients with HIV and lymphoma should be considered for immunotherapy, provided that their HIV infection is well controlled.

- Patients should be evaluated for HBV and HCV prior to initiating immunotherapy. If patients are positive for HBV or HCV, immunotherapy may be considered provided that an appropriate antiviral is initiated.

- There was consensus that patients with active inflammatory disorders should not receive CAR $\mathrm{T}$ cell therapy.

- There was consensus that elderly patients should be considered for immunotherapy and for stem cell transplant.

\section{PATIENT SUPPORT AND QUALITY OF LIFE ISSUES}

Immunotherapies can be complex in terms of their administration and monitoring requirements, and often require extensive education for both providers and patients to ensure optimal outcomes. As AEs that arise during immunotherapeutic treatment have unique underlying mechanisms compared with AEs that arise during treatment with chemotherapy and/or radiotherapy, it is imperative that patients can effectively communicate with healthcare providers concerning the treatments they have received or are currently receiving as well as the symptoms they may be experiencing. Additionally, many patients receive immunotherapies only in advanced disease settings after being heavily treated previously, which brings forth a number of quality of life (QOL) considerations.

Immunotherapy encompasses multiple complex treatment modalities that require education for healthcare providers to ensure optimal patient management. Education is especially important for management of AEs that may arise during treatment with an immunotherapy, as these toxicities are predicated on different underlying biological mechanisms compared with similar events that arise during treatment with other modalities. ${ }^{183}$ To assist in this regard, many programs currently advocate for increased patient outcome reporting to assess toxicities as well as value. ${ }^{223}$
As immunotherapies for lymphoma are numerous, diverse, and approved for specific settings only, confusion on the part of both patients and healthcare professionals can exist regarding appropriate treatment scheduling. In general, many patients with cancer are unaware of the opportunities for treatment with immunotherapy for their given disease. According to patient attendee survey data presented by Cancer Support Community at the 2017 SITC Annual Meeting and Pre-Conference Programs, $47.2 \%$ of respondents were not confident in immunotherapy being appropriate for treatment of their disease, and only $33 \%$ of respondents had discussed immunotherapy as an option with their physician. ${ }^{224}$

A patient's health-related quality of life (HRQOL) is an important consideration during the administration of any therapy. There has been a general trend in the modern era towards improvement in assessing HRQOL through patient self-reporting both during clinical trials and during standard treatment. ${ }^{225} 226$ A number of tools have been developed to assess patient-reported outcomes of toxicity and HRQOL, including the patient-reported outcomes Common Terminology Criteria for Adverse Events (PRO-CTCAE), ${ }^{227}$ the European Organization for the Research and Treatment of Cancer Quality of Life Questionnaire Core 30 (EORTC-QLQ-C30), ${ }^{228}$ and the MD Anderson Symptom inventory (MDASI) ${ }^{229}$ In studies of patients with lymphoma receiving immunotherapies, immunotherapies appear to compare favorably to other therapies. HRQOL data from the phase III MAVORIC trial on patients with cutaneous TCL showed that mogamulizumab compared favorably to chemotherapy at all stages of treatment. ${ }^{230}$ Additionally, HRQOL for patients receiving CAR T cell therapy was not significantly different from HRQOL in patients receiving autoSCT or alloSCT in a study of 45 patients with hematological malignancies. ${ }^{231}$

CAR T cell therapies hold unique considerations for patient QOL beyond typical concerns about AEs and financial toxicity. Due to the nature of CAR T cell therapy as populations of living cells within the body and the possibility of severe AEs such as CRS and ICANS, the approved products are all sold under a risk evaluation and mitigation strategy (REMS) that mandates patients remain within 2 hours of the treatment facility where CAR T cell therapy was administered for at least 4 weeks after CAR $\mathrm{T}$ cell infusion. ${ }^{232} 233$ These REMS for each product also mandate monitoring requirements: once daily for 1 week post-infusion for axicabtagene ciloleucel and brexucabtagene autoleucel, and two to three times in the week postinfusion for tisagenlecleucel. ${ }^{111} 113$ Furthermore, patients treated with CAR T cells must carry a wallet card at all times to ensure correct triage and specialist care in an emergency. ${ }^{232} 233$ However, though many patients had symptoms of fatigue and some may have prolonged cytopenias and hypogammaglobulinemia, the majority of toxicities occur in the first 2-3weeks after infusion. This is quite favorable compared with the often prolonged courses of typical chemotherapy regimens, or the very 
long convalescence period required for most patients after alloSCT. CAR T cell therapies do hold a significant risk of financial toxicity, however, given their high cost and considerable requirements for patient monitoring. ${ }^{234}$

The financial burden that patients with cancer bear has increased dramatically in recent times, partially due to the introduction of novel, high-cost therapies. In many cases, recently introduced therapies (such as CAR T cell therapies) present difficulties in obtaining adequate reimbursement from health insurance or programs such as Medicare and Medicaid. ${ }^{235} 236$ Financial toxicity can, in turn, reduce the quality of care that patients can afford and reduce patient QOL. ${ }^{237-239}$ CAR T cell therapies are expensive, in the range of $\$ 373000$ for lymphoma treatment, not including post-treatment care and management of toxicities. With difficulties in obtaining payer support from insurers or Medicaid, the cost of CAR T cell therapies may represent an insurmountable obstacle for a number of patients who would otherwise be well-suited to the therapy. ${ }^{240} 241$

Considerations of the value of immunotherapy is beyond the scope of this manuscript, but as CAR T cell therapies have provided durable responses in patients with lymphoma, a limited discussion concerning the introduction of 'off-label' CAR T cell therapy into earlier lines of treatment may be warranted. Current FDA approvals limit axicabtagene ciloleucel and tisagenlecleucel to third-line or later treatment options in patients with select NHLs. ${ }^{232} 233$ There are seemingly no biological limitations, however, preventing the introduction of CAR $\mathrm{T}$ cell therapies into earlier lines of treatment, other than the limitation of potentially fatal AEs compared with those observed via induction chemotherapy, which is effective in a significant number of patients with lymphoma.

\section{Panel recommendations}

- There was consensus that patient reporting on toxicity and QOL issues should be emphasized for patients receiving immunotherapy, and that these patients should receive educational tools regarding immunotherapy and these potential issues.

- There was consensus that financial burden influences the availability and scheduling of immunotherapy treatments. Insurance coverage was noted as a major financial barrier.

- There was consensus that the extended time needed for cell therapy manufacturing and high financial burden are likely to impair clinical trials of cell-based therapies, such as CAR T cell therapy.

\section{CONCLUSION}

The rapid introduction and clinical implementation of new immunotherapies has revolutionized oncology and led to tremendous improvements in outcomes specifically for patients with lymphoma, especially in the advanced setting. Multiple novel immunotherapeutic strategies have been approved or are in development for the treatment of patients with Hodgkin and NHLs, as well as CLL, including mAbs, ICIs, ADCs, and CAR T cell therapies. Further innovations will likely bring about even greater improvements for patient outcomes. The treatment recommendations within this manuscript represent the consensus of the SITC Lymphoma Immunotherapy Guideline expert panel based on the evidence available at the time of publication. As the field continues to move forward, the expert panel will evaluate the potential need for updates to recommendations in this CPG.

\section{Author affiliations}

${ }^{1}$ Department of Lymphoma and Myeloma, University of Texas MD Anderson Cancer Center, Houston, Texas, USA

${ }^{2}$ Division of Hematology, Department of Internal Medicine, Mayo Clinic Cancer Center, Rochester, Minnesota, USA

${ }^{3}$ Hematology and Oncology, Icahn School of Medicine at Mount Sinai, New York City, New York, USA

${ }^{4}$ Department of Pediatrics, Medicine, Pathology, Microbiology and Immunology and Cell Biology, New York Medical College At Maria Fareri Children's Hospital, New York City, New York, USA

${ }^{5}$ Department of Medicine, Hematology-Oncology Division, Wilmot Cancer Institute University of Rochester Medical Center, Rochester, New York, USA

${ }^{6}$ Department of Medicine Section of Hematology/Oncology, University of Chicago, Chicago, Illinois, USA

${ }^{7}$ Division of Oncology, Department of Medicine, Stanford University School of Medicine, Stanford, California, USA

${ }^{8}$ Cell Therapy and Transplant and Division of Hematology Oncology, Abramson Cancer Center, University of Pennsylvania, Philadelphia, Pennsylvania, USA

${ }^{9}$ Division of Hematology/Oncology, Weill Cornell Medical College, New York City, New York, USA

${ }^{10}$ Founder and CEO of HomeX, Chicago, Illinois, USA

Correction notice This paper has been updated since first publish to amend the Panel recommendations for Burkitt's lymphoma.

Twitter Joshua Brody joshuabrodyMD, SITC @sitcancer

Acknowledgements The authors acknowledge SITC staff for their contributions including Peter Intile, PhD; Ben Labbe, PhD; and Rachel Lieberman, PhD for medical writing and Angela Kilbert; Lionel Lim; and Sam Million-Weaver, PhD for project management and editorial assistance. Additionally, the authors wish to thank the society for supporting the manuscript development.

Contributors All authors served on the SITC Lymphoma Immunotherapy Guideline Expert Panel, drafted content, and provided critical review during the manuscript development. MRB and SSN provided leadership as Chairs of the Expert Panel and provided guidance on the manuscript structure and content and thus are first and last authors; all other authors contributed equally to the manuscript development and review and therefore are listed alphabetically by last name. MW was the patient advocate representative. All authors have read and approved the final version of this manuscript.

Funding The authors have not declared a specific grant for this research from any funding agency in the public, commercial or not-for-profit sectors.

Competing interests SMA-Research funding to institution: Bristol Myers Squibb, Seattle Genetics, Affimed, Trillium, Al Therapeutics, ADC Therapeutics, Regeneron. MSC-Advisory board: Bayer, Celgene, and Nektar; Speaker honoraria: Jazz Pharmaceuticals. JWF-NSMC activity: Astellas Pharma, Bayer; Research support: Seattle Genetics. JPK-Consulting fees: Merck, Verastem; Research support: iTeos Therapeutics, Merck, Verastem; Speaker's bureau: Kite. RL-Consulting: BeiGene, Corvus, Five Prime, Innate Pharma, Immune Design, Kite Pharma; Grant/research support: Bristol-Myers, Squibb, Dynavax, Pfizer, and Pharmacyclics; Stockholder: Merck. SSN-Advisory board/consultant: Allogene, Bristol-Myers Squibb, Celgene, Cell Medica/Kuur, Gilead, Incyte, Kite Pharma, Merck, Novartis, Pfizer, Precision BioSciences, Unum Therapeutics; Research support: Acerta, Allogene, Bristol-Myers Squibb, Gilead, Karus, Kite Pharma, Merck, Precision BioSciences, and Unum Therapeutics; Royalties: Takeda Pharmaceuticals (patents related to immune cell therapy). DLP-Honorarium/advisory board: Incyte, Kite Pharma, Novartis, Janssen, Glenmark; Research funding: Novartis; Patent: CD19 CAR T cells; Royalty: Novartis; Employment and stock/options: Genentech/Roche (spouse employment). 
KVB-Advisory board: Cellectis; Financial interest: Hemogenyx; Research support: Novartis. SA, JB, MRB, and MW-Nothing to disclose. SITC staff members: PI, AK, BL, $\mathrm{RL}$, LL, and SMW-Nothing to disclose.

Patient consent for publication Not required.

Provenance and peer review Not commissioned; externally peer reviewed.

Open access This is an open access article distributed in accordance with the Creative Commons Attribution Non Commercial (CC BY-NC 4.0) license, which permits others to distribute, remix, adapt, build upon this work non-commercially, and license their derivative works on different terms, provided the original work is properly cited, appropriate credit is given, any changes made indicated, and the use is non-commercial. See http://creativecommons.org/licenses/by-nc/4.0/.

\section{ORCID iD}

Mitchell S Cairo http://orcid.org/0000-0002-2075-434X

\section{REFERENCES}

1 Leukemia \& Lymphoma Society. Facts and statistics, 2019. Available: http://www.lls.org/facts-and-statistics/facts-andstatistics-overview

2 American Cancer Society. Cancer statistics center, 2019. Available: https://cancerstatisticscenter.cancer.org/

3 Boyiadzis M, Bishop MR, Abonour R, et al. The Society for immunotherapy of cancer consensus statement on immunotherapy for the treatment of hematologic malignancies: multiple myeloma, Iymphoma, and acute leukemia. J Immunother Cancer 2016;4:90.

4 The Society for Immunotherapy of Cancer. SITC cancer immunotherapy guidelines. Available: https://www.sitcancer.org/ research/cancer-immunotherapy-guidelines

5 Institute of Medicine, Graham R, Mancher M, Wolman DM, et al, eds. Clinical practice guidelines we can trust. Washington, DC: The National Academies Press, 2011: 290.

6 Vist GE, Bryant D, Somerville L, et al. Outcomes of patients who participate in randomized controlled trials compared to similar patients receiving similar interventions who do not participate. Cochrane Database of Systematic Reviews 2008;60.

7 Armitage JO. Staging non-Hodgkin lymphoma. CA: A Cancer Journal for Clinicians 2005;55:368-76.

8 Connors JM. State-of-the-art therapeutics: Hodgkin's lymphoma. J Clin Oncol 2005;23:6400-8.

9 Kwee TC, Kwee RM, Nievelstein RAJ. Imaging in staging of malignant lymphoma: a systematic review. Blood 2008;111:504-16.

10 Casulo C, Maragulia J, Zelenetz AD. Incidence of hypogammaglobulinemia in patients receiving rituximab and the use of intravenous immunoglobulin for recurrent infections. Clin Lymphoma Myeloma Leuk 2013:13:106-11.

11 Ullmann AJ, Schmidt-Hieber M, Bertz H, et al. Infectious diseases in allogeneic haematopoietic stem cell transplantation: prevention and prophylaxis strategy guidelines 2016. Ann Hematol 2016;95:1435-55.

12 National Comprehensive Cancer Network. B-Cell lymphomas, 2018. Available: https://www.nccn.org/professionals/physician_gls/pdf/ b-cell.pdf

13 Csapo M, Lazar L. Chemotherapy-Induced cardiotoxicity: pathophysiology and prevention. Med Pharm Rep 2014;87:135-42.

14 Yusuf SW, Sami S, Daher IN. Radiation-Induced heart disease: a clinical update. Cardiol Res Pract 2011;2011:317659-9.

15 Salem J-E, Manouchehri A, Moey M, et al. Cardiovascular toxicities associated with immune checkpoint inhibitors: an observational, retrospective, pharmacovigilance study. Lancet Oncol 2018;19:1579-89.

16 Canellos GP, Anderson JR, Propert KJ, et al. Chemotherapy of advanced Hodgkin's disease with MOPP, ABVD, or MOPP alternating with ABVD. N Engl J Med 1992;327:1478-84.

17 Canellos GP, Niedzwiecki D. Long-Term follow-up of Hodgkin's disease trial. N Engl J Med 2002;346:1417-8.

18 Millennium Pharmaceuticals, Inc, Seattle Genetics, Inc, Takeda. A frontline therapy trial in participants with advanced classical Hodgkin lymphoma 2017 [updated April 20], 2017. Available: https://ClinicalTrials.gov/show/NCT01712490

19 Connors JM, Jurczak W, Straus DJ, et al. Brentuximab vedotin with chemotherapy for Stage III or IV Hodgkin's lymphoma. N Engl J Med 2018:378:331-44.

20 Seattle Genetics, Inc. ADCETRIS prescribing information Bothell, WA. Available: https://www.accessdata.fda.gov/scripts/cder/daf/ index.cfm?event=overview. process\&App|No $=125388$
21 Seattle Genetics, Inc, Millennium Pharmaceuticals, Inc. A Phase 3 Study of Brentuximab Vedotin (SGN-35) in Patients at high risk of residual Hodgkin lymphoma following stem cell transplant (The AETHERA Trial) 2014 [updated August 31]. Available: https:// ClinicalTrials.gov/show/NCT01100502

22 Moskowitz CH, Walewski J, Nademanee A, et al. Five-year pfs from the AETHERA trial of brentuximab vedotin for Hodgkin lymphoma at high risk of progression or relapse. Blood 2018;132:2639-42.

23 Seattle Genetics, Inc, Millennium Pharmaceuticals, Inc. A pivotal open-label trial of brentuximab vedotin for Hodgkin lymphoma 2010 [updated August]. Available: https://ClinicalTrials.gov/show/ NCT00848926

24 Gopal AK, Chen R, Smith SE, et al. Durable remissions in a pivotal phase 2 study of brentuximab vedotin in relapsed or refractory Hodgkin lymphoma. Blood 2015;125:1236-43.

25 Squibb B-M. Study of Nivolumab in Patients With Classical Hodgkin's Lymphoma (Registrational) 2017 [updated August 31]. Available: https://ClinicalTrials.gov/show/NCT02181738

26 Squibb B-M, Janssen LP. An investigational immuno-therapy study to determine the safety and effectiveness of nivolumab and daratumumab in patients with multiple mye loma 2022 [updated January 13]. Available: https://ClinicalTrials.gov/show/ NCT01592370

27 Armand P, Engert A, Younes A, et al. Nivolumab for relapsed/ refractory classic Hodgkin lymphoma after failure of autologous hematopoietic cell transplantation: extended follow-up of the Multicohort single-arm phase II CheckMate 205 trial. J Clin Oncol 2018:36:1428-39.

28 Squibb B-M. OPDIVO prescribing information. Available: https:// www.accessdata.fda.gov/scripts/cder/daf/index.cfm?event= overview.process\&AppINo $=125554$

29 Seattle Genetics, Inc. Squibb B-M. A Study of Brentuximab Vedotin Combined With Nivolumab for Relapsed or Refractory Hodgkin Lymphoma 2018 [updated March 1]. Available: https://ClinicalTrials. gov/show/NCT02572167

30 Herrera AF, Moskowitz AJ, Bartlett NL, et al. Interim results of brentuximab vedotin in combination with nivolumab in patients with relapsed or refractory Hodgkin lymphoma. Blood 2018:131:1183-94.

31 Merck Sharp \& Dohme Corp. Study of pembrolizumab (MK-3475) in participants with relapsed or refractory class ical Hodgkin Lymphoma (MK-3475-087/KEYNOTE-087) 2021 [updated April 20]Merck Sharp \& Dohme Corp. Available: https://ClinicalTrials.gov/ show/NCT02453594

32 Chen R, Zinzani PL, Fanale MA, et al. Phase II study of the efficacy and safety of pembrolizumab for relapsed/refractory classic Hodgkin lymphoma. J Clin Oncol 2017;35:2125-32.

33 Merck \& Co. Inc. Pembrolizumab (KEYTRUDA) prescribing information, 2017. Available: https://www.accessdata.fda.gov/ scripts/cder/daf/index.cfm?event=overview. process\&AppINo= 125514

34 McLaughlin P, Grillo-López AJ, Link BK, et al. Rituximab chimeric anti-CD20 monoclonal antibody therapy for relapsed indolent lymphoma: half of patients respond to a four-dose treatment program. J Clin Oncol 1998;16:2825-33.

35 Piro LD, White CA, Grillo-López AJ, et al. Extended rituximab (anti-CD20 monoclonal antibody) therapy for relapsed or refractory low-grade or follicular non-Hodgkin's lymphoma. Ann Oncol 1999;10:655-61.

36 Davis TA, Grillo-López AJ, White CA, et al. Rituximab anti-CD20 monoclonal antibody therapy in non-Hodgkin's lymphoma: safety and efficacy of re-treatment. J Clin Oncol 2000;18:3135-43.

37 Genentech. RITUXAN prescribing information South San Francisco, CA. Available: https://www.accessdata.fda.gov/scripts/cder/daf/ index.cfm?event=overview.process\&App|No=103705

38 Marcus R, Imrie K, Belch A, et al. CVP chemotherapy plus rituximab compared with CVP as first-line treatment for advanced follicular lymphoma. Blood 2005;105:1417-23.

39 Lymphoma Study Association, HOVON Dutch Haemato-Oncology Association, German Low Grade Lymphoma Study Group. Primary rituximab and maintenance 2007 [updated May]. Available: https:// ClinicalTrials.gov/show/NCT00140582

40 Salles G, Seymour JF, Offner F, et al. Rituximab maintenance for 2 years in patients with high tumour burden follicular lymphoma responding to rituximab plus chemotherapy (PRIMA): a phase 3 , randomised controlled trial. The Lancet 2011:377:42-51.

41 Hochster H, Weller E, Gascoyne RD, et al. Maintenance rituximab after cyclophosphamide, vincristine, and prednisone prolongs progression-free survival in advanced indolent lymphoma: results of the randomized phase III ECOG1496 study. J Clin Oncol 2009;27:1607-14. 
42 Eastern Cooperative Oncology Group, National Cancer Institute Cancer and Leukemia Group B. Combination chemotherapy with or without monoclonal antibody therapy in treating older patients with non-hodgkin's lymphoma. Available: https://ClinicalTrials.gov/show/ NCT00003150

43 Coiffier B, Lepage E, Brière J, et al. CHOP chemotherapy plus rituximab compared with $\mathrm{CHOP}$ alone in elderly patients with diffuse large-B-cell lymphoma. N Engl J Med Overseas Ed 2002;346:235-42.

$44 \mathrm{NCIC}$ Clinical Trials Group, Canadian Cancer Trials Group. Combination chemotherapy with or without rituximab in treating patients with non-hodgkin's lymphoma 2010 [updated December]. Available: https://ClinicalTrials.gov/show/NCT00064116

45 Habermann TM, Weller EA, Morrison VA, et al. Rituximab-CHOP versus $\mathrm{CHOP}$ alone or with maintenance rituximab in older patients with diffuse large B-cell lymphoma. J Clin Oncol 2006;24:3121-7.

46 Pfreundschuh M, Trümper L, Österborg A, et al. CHOP-like chemotherapy plus rituximab versus CHOP-like chemotherapy alone in young patients with good-prognosis diffuse large-Bcell lymphoma: a randomised controlled trial by the MabThera international trial (MInT) group. Lancet Oncol 2006;7:379-91.

47 Dunleavy K, Pittaluga S, Maeda LS, et al. Dose-adjusted EPOCHrituximab therapy in primary mediastinal B-cell lymphoma. $N$ Engl $J$ Med 2013;368:1408-16.

48 Giulino-Roth L, O'Donohue T, Chen Z, et al. Outcomes of adults and children with primary mediastinal B-cell lymphoma treated with dose-adjusted EPOCH-R. Br J Haematol 2017;179:739-47.

49 Benkerrou M, Jais JP, Leblond V, et al. Anti-B-cell monoclonal antibody treatment of severe posttransplant B-lymphoproliferative disorder: prognostic factors and long-term outcome. Blood 1998:92:3137-47.

50 Tsai DE, Hardy CL, Tomaszewski JE, et al. Reduction in immunosuppression as initial therapy for posttransplant lymphoproliferative disorder: analysis of prognostic variables and long-term follow-up of 42 adult patients1. Transplantation 2001;71:1076-88

51 Mamzer-Bruneel MF, Lomé C, Morelon E, et al. Durable remission after aggressive chemotherapy for very late post-kidney transplant lymphoproliferation: a report of 16 cases observed in a single center. J Clin Oncol 2000;18:3622-32.

52 Swinnen LJ, Mullen GM, Carr TJ, et al. Aggressive treatment for postcardiac transplant lymphoproliferation. Blood 1995;86:3333-40.

53 Perrine SP, Hermine O, Small T, et al. A phase 1/2 trial of arginine butyrate and ganciclovir in patients with Epstein-Barr virusassociated lymphoid malignancies. Blood 2007;109:2571-8.

54 Choquet S, Trappe R, Leblond V, et al. CHOP-21 for the treatment of post-transplant lymphoproliferative disorders following solid organ transplantation. Haematologica 2007;92:273-4.

55 Fohrer C, Caillard S, Koumarianou A, et al. Long-Term survival in post-transplant lymphoproliferative disorders with a dose-adjusted ACVBP regimen. Br J Haematol 2006;134:602-12.

56 Viracta Therapeutics, Inc. Dose escalation \& expansion study of oral VRx-3996 \& Valganciclovir in subjects with EBV-Associated Iymphoid malignancies 2020 [updated January]. Available: https:// ClinicalTrials.gov/show/NCT03397706

57 M. D. Anderson Cancer Center, National Cancer Institute. Ibrutinib and rituximab in treating patients with relapsed or refractory mantle cell lymphoma or older patients with newly diagnosed mantle cell lymphoma 2020 [updated July 31]. Available: https://ClinicalTrials. gov/show/NCT01880567

58 Wang ML, Lee $\mathrm{H}$, Chuang $\mathrm{H}$, et al. Ibrutinib in combination with rituximab in relapsed or refractory mantle cell lymphoma: a singlecentre, open-label, phase 2 trial. Lancet Oncol 2016;17:48-56.

59 Griffiths R, Mikhael J, Gleeson M, et al. Addition of rituximab to chemotherapy alone as first-line therapy improves overall survival in elderly patients with mantle cell lymphoma. Blood 2011:118:4808-16.

60 Robak T, Huang H, Jin J, et al. Bortezomib-based therapy for newly diagnosed mantle-cell lymphoma. N Engl J Med 2015;372:944-53.

61 Le Gouill S, Thieblemont C, Oberic L, et al. Rituximab after autologous stem-cell transplantation in mantle-cell lymphoma. $N$ Engl J Med 2017:377:1250-60.

62 Celltrion, Inc. TRUXIMA prescribing information. Available: https:// www.accessdata.fda.gov/scripts/cder/daf/index.cfm?event= overview. process\&AppINo $=761088$

63 Pfizer, Inc. RUXIENCE prescribing information. Available: https:// www.accessdata.fda.gov/scripts/cder/daf/index.cfm?event= overview. process\&AppINo $=761103$

64 Stebbing J, Mainwaring PN, Curigliano G, et al. Understanding the role of comparative clinical studies in the development of oncology biosimilars. J Clin Oncol 2020;38:1070-80.
65 Dutta B, Huys I, Vulto AG, et al. Identifying key benefits in European off-patent biologics and biosimilar markets: it is not only about price! BioDrugs 2020;34:159-70.

66 Genentech. RITUXAN HYCELA prescribing information South San Francisco. Available: https://www.accessdata.fda.gov/scripts/cder/ daf/index.cfm?event=overview. process\&AppINo=761064

67 Genentech, IncRoche Pharma AG. A Study to Investigate the Efficacy and Safety of Bendamustine Compared With Bendamustine+Obinutuzumab (GA101) in Participants With Rituximab-Refractory, Indolent Non-Hodgkin's Lymphoma (GADOLIN) 2014 [updated September 30]. Available: https:// ClinicalTrials.gov/show/NCT01059630

68 Friedberg JW, Cohen P, Chen L, et al. Bendamustine in patients with rituximab-refractory indolent and transformed non-hodgkin's lymphoma: results from a phase ii multicenter, single-agent Study. $J$ Clin Oncol 2008;26:204-10.

69 Sehn LH, Chua N, Mayer J, et al. Obinutuzumab plus bendamustine versus bendamustine monotherapy in patients with rituximabrefractory indolent non-Hodgkin lymphoma (GADOLIN): a randomised, controlled, open-label, multicentre, phase 3 trial. Lancet Oncol 2016;17:1081-93.

70 Genentech. GAZYVA prescribing information South San Francisco, CA. Available: https://www.accessdata.fda.gov/scripts/cder/daf/ index.cfm?event=overview. process\&AppINo $=125486$

71 Hoffmann-La Roche, German Low Grade Lymphoma Study Group, Institute of Cancer Research, United Kingdom. A study of obinutuzumab (RO5072759) plus chemotherapy in comparison with rituximab plus chemotherapy followed by obinutuzumab or rituximab maintenance in patients with untreated advanced indolent non-hodgkin's lymphoma (GALLIUM) 2016 [updated February 1]. Available: https://ClinicalTrials.gov/show/ NCT01332968

72 Marcus R, Davies A, Ando K, et al. Obinutuzumab for the firstline treatment of follicular lymphoma. $N$ Engl J Med Overseas Ed 2017;377:1331-44.

73 Fondazione Italiana Linfomi ONLUS. La-Roche H. A study of Obinutuzumab in combination with CHOP chemotherapy versus rituximab with $\mathrm{CHOP}$ in participants with $\mathrm{CD} 20$-positive diffuse large B-cell lymphoma (GOYA). Available: https://clinicaltrials.gov/ ct2/show/NCT01287741

74 Vitolo $U$, Trněný $M$, Belada $D$, et al. Obinutuzumab or rituximab plus cyclophosphamide, doxorubicin, vincristine, and prednisone in previously untreated diffuse large B-cell lymphoma. J Clin Oncol 2017;35:3529-37.

75 Alcindor T, Witzig TE. Radioimmunotherapy with Yttrium-90 Ibritumomab tiuxetan for patients with relapsed cd20+ B-Cell nonhodgkin's lymphoma. Curr Treat Options Oncol 2002;3:275-82.

76 Witzig T, Gordon L, Wiseman G, eds. Reduced dose Zevalin is safe and effective in patients with relapsed or refractory, low grade, follicular or CD2O (+) transformed B cell non-Hodgkin's lymphoma (L/F/T NHL) and mild thrombocytopenia. Blood. WASHINGTON DC 20036 USA: AMER SOC HEMATOLOGY 1900 MSTREET. NW SUITE 200, 2000

77 Witzig T, White C, Gordon L. Response to Zevalin is superior to response to rituximab regardless of age and extent of disease. Proc Am Soc Clin Oncol 2001.

78 Witzig T, White C, Gordon L. Zevalin radioimmunotherapy of rituximab-refractory follicular non-Hodgkin's lymphoma. Blood 2000;96:507a

79 Spectrum Pharms. ZEVALIN prescribing information. Available: https://www.accessdata.fda.gov/scripts/cder/daf/index.cfm?event= overview. process\&App|No $=125019$

80 Bayer. Treatment With [90]Y-Ibritumomab Tiuxetan Versus no Treatment in Patients With Follicular Non Hodgkin Lymphoma (Stage III or IV) Having Achieved a Partial or Complete Remission After First Line Chemotherapy, 2008. Available: https://clinicaltrials. gov/ct2/show/NCT00185393

81 Morschhauser F, Radford J, Van Hoof A, et al. Phase III trial of consolidation therapy with yttrium-90-ibritumomab tiuxetan compared with no additional therapy after first remission in advanced follicular lymphoma. J Clin Oncol 2008;26:5156-64.

82 GlaxoSmithKline LLC, Food and Drug Administration. Glaxosmithkline LLC; withdrawal of approval of the indication for treatment of patients with relapsed or refractory, low grade, follicular, or transformed CD20 positive non-Hodgkin's lymphoma who have not received prior rituximab; BEXXAR. Federal Register 2013;78:63226-7.

83 Seattle Genetics Inc, Millennium Pharmaceuticals Inc. A phase 2 open label trial of Brentuximab Vedotin (SGN-35) for systemic anaplastic large cell lymphoma, 2010. Available: https://clinicaltrials. gov/ct2/show/NCT00866047 
84 Pro B, Advani R, Brice P, et al. Five-year results of brentuximab vedotin in patients with relapsed or refractory systemic anaplastic large cell lymphoma. Blood 2017;130:2709-17.

85 Seattle Genetics, Inc, Millennium Pharmaceuticals, Inc. ECHELON-2: A Comparison ofBrentuximab Vedotin and CHP With Standard-of-care CHOP in the Treatment of Patients With CD30-positive Mature T-cell Lymphomas 2018 [updated August 15] Available: https://ClinicalTrials.gov/show/NCT01777152

86 Prince HM, Kim YH, Horwitz SM, et al. Brentuximab vedotin or physician's choice in CD30-positive cutaneous T-cell lymphoma (ALCANZA): an international, open-label, randomised, phase 3, multicentre trial. Lancet 2017;390:555-66.

87 Millennium Pharmaceuticals, Inc, Seattle Genetics, Inc, Takeda. A Phase 3 Trial of Brentuximab Vedotin(SGN-35) Versus Physician's Choice (Methotrexate or Bexarotene) in Participants With CD30Positive Cutaneous T-Cell Lymphoma (ALCANZA Study) 2016 [updated May 31]. Available: https://ClinicalTrials.gov/show/ NCT01578499

88 Jacobsen ED, Sharman JP, Oki Y, et al. Brentuximab vedotin demonstrates objective responses in a phase 2 study of relapsed/refractory DLBCL with variable CD30 expression. Blood 2015;125:1394-402.

89 Berger GK, McBride A, Lawson S, et al. Brentuximab vedotin for treatment of non-Hodgkin lymphomas: a systematic review. Crit Rev Oncol Hematol 2017;109:42-50.

90 Hoffman-La Roche, ClinicalTrials.gov Bethesda (MD): Nationa Library of Medicine (US). Identifier NCT02257567, a study of Polatuzumab Vedotin (DCDS4501A) in combination with rituximab or Obinutuzumab plus bendamustine in participants with relapsed or refractory follicular or diffuse large B-cell lymphoma.

91 Sehn LH, Herrera AF, Flowers CR, et al. Polatuzumab Vedotin in relapsed or refractory diffuse large B-cell lymphoma. J Clin Oncol 2020;38:155-65.

92 Genentech. POLIVY prescribing information. Available: https://www accessdata.fda.gov/scripts/cder/daf/index.cfm?event=overview. process\&App|No=761121

93 Kyowa Kirin Pharmaceutical Development, Inc. Study of KW-0761 versus vorinostat in relapsed/refractory CTCL 2017 [updated March]. Available: https://ClinicalTrials.gov/show/NCT01728805

$94 \mathrm{Kim}$ YH, Bagot M, Pinter-Brown L, et al. Mogamulizumab versus vorinostat in previously treated cutaneous T-cell lymphoma (MAVORIC): an international, open-label, randomised, controlled phase 3 trial. Lancet Oncol 2018;19:1192-204.

95 Kyowa K. POTELIGEO prescribing information Tokyo, Japan. Available: https://www.accessdata.fda.gov/scripts/cder/daf/index. cfm?event $=$ overview. process \&ApplNo $=761051$

96 Armand P, Rodig S, Melnichenko V, et al. Pembrolizumab in relapsed or refractory primary mediastinal large B-cell lymphoma. $J$ Clin Oncol 2019:37:3291-9.

97 Merck Sharp \& Dohme Corp. Study of pembrolizumab (MK-3475) in participants with relapsed or refractory primary mediastinal large b-cell lymphoma or relapsed or refractory richter syndrome (MK-3475-170/KEYNOTE-170) 2019 [updated June 29]. Available: https://ClinicalTrials.gov/show/NCT02576990

98 Celgene. A study to determine the efficacy and safety of lenalidomide in patients with mantle cell $\mathrm{nhl}$ who have relapsed or progressed after treatment with bortezomib or are refractory to bortezomib. The "EMERGE" Trial 2016 [updated April 6]. Available: https://ClinicalTrials.gov/show/NCT00737529

99 Witzig TE, Luigi Zinzani P, Habermann TM, et al. Long-Term analysis of phase II studies of single-agent lenalidomide in relapsed/ refractory mantle cell lymphoma. Am J Hematol 2017;92:E575-83.

100 Celgene. Lenalidomide (REVLIMID) prescribing information. Available: https://www.accessdata.fda.gov/scripts/cder/daf/index. cfm?event $=$ overview. process \&ApplNo $=021880$

101 Celgene. Rituximab Plus Lenalidomide for Patients With Relapsed Refractory Indolent Non-Hodgkin's Lymphoma (Follicular Lymphoma and Marginal Zone Lymphoma) 2018 [updated June 22] Available: https://ClinicalTrials.gov/show/NCT01938001

102 Leonard JP, Trneny M, Izutsu K, et al. Augment: a phase III study of lenalidomide plus rituximab versus placebo plus rituximab in relapsed or refractory indolent lymphoma. J Clin Oncol 2019;37:1188-99.

103 Celgene. Lenalidomide Plus Rituximab Followed by Lenalidomide Versus Rituximab Maintenance for Relapsed/Refractory Follicular, Marginal Zone or Mantle Cell Lymphoma 2023 [updated April 8]. Available: https://ClinicalTrials.gov/show/NCT01996865

104 Andorsky DJ, Coleman M, Yacoub A, et al. MAGNIFY: phase IIIB interim analysis of induction R2 followed by maintenance in relapsed/refractory indolent non-Hodgkin lymphoma. J Clin Oncol 2019;37. 7513.
105 Celgene, The Lymphoma Academic Research Organisation. Combined rituximab and lenalidomide treatment for untreated patients with follicular lymphoma (relevance). Available: https:// clinicaltrials.gov/ct2/show/NCT01476787

106 The Lymphoma Academic Research Organisation, Celgene. A phase 3 open label randomized study to compare the efficacy and safety of rituximab plus lenalidomide (CC-5013) versus rituximab plus chemotherapy followed by rituximab in subjects with previously untreated follicular lymphoma (relevance). Available: https://clinicaltrials.gov/ct2/show/NCT01650701

107 Morschhauser F, Fowler NH, Feugier P, et al. Rituximab plus lenalidomide in advanced untreated follicular lymphoma. $N$ Engl J Med 2018;379:934-47

108 Czuczman MS, Trněný M, Davies A, et al. A phase 2/3 multicenter, randomized, open-label study to compare the efficacy and safety of lenalidomide versus investigator's choice in patients with relapsed or refractory diffuse large B-cell lymphoma. Clin Cancer Res 2017;23:4127-37

109 Locke FL, Ghobadi A, Jacobson CA, et al. Long-Term safety and activity of axicabtagene ciloleucel in refractory large B-cell lymphoma (ZUMA-1): a single-arm, multicentre, phase 1-2 trial. Lancet Oncol 2019;20:31-42.

110 Kite, A Gilead Company, Gilead Sciences. Safety and Efficacy of KTE-C19 in Adults With Refractory Aggressive Non-Hodgkin Lymphoma 2020 [updated August]. Available: https://ClinicalTrials. gov/show/NCT02348216

111 Kite Pharma, Incorporated. YESCARTA (axicabtagene ciloleucel): food and drug administration, 2017. Available: https://www.fda.gov/ vaccines-blood-biologics/cellular-gene-therapy-products/yescartaaxicabtagene-ciloleucel

112 Schuster SJ, Bishop MR, Tam CS, et al. Tisagenlecleucel in adult relapsed or refractory diffuse large B-cell lymphoma. N Engl J Med 2019;380:45-56.

113 Novartis Pharmaceuticals. KYMRIAH (tisagenlecleucel): food and drug administration, 2018. Available: https://www.fda.gov/ vaccines-blood-biologics/cellular-gene-therapy-products/kymriahtisagenlecleucel

114 Food and Drug Administration. TECARTUS (brexucabtagene autoleucel). Available: https://www.fda.gov/vaccines-bloodbiologics/cellular-gene-therapy-products/tecartus-brexucabtageneautoleucel

115 Kite, A Gilead Company, Gilead Sciences. A phase 2 multicenter study evaluating subjects with relapsed/refractory mantle cell lymphoma 2019 [updated July 24]. Available: https://ClinicalTrials. gov/show/NCT02601313

116 Wang M, Munoz J, Goy A, et al. KTE-X19 CAR T-cell therapy in relapsed or refractory mantle-cell lymphoma. $N$ Engl J Med 2020;382:1331-42.

117 Morphosys AG. A study to evaluate the safety and efficacy of lenalidomide with MOR00208 in patients with R-R DLBCL (L-MIND). Available: https://clinicaltrials.gov/ct2/show/ NCT02399085

118 Salles G, Duell J, González Barca E, et al. Tafasitamab plus lenalidomide in relapsed or refractory diffuse large B-cell lymphoma (L-MIND): a multicentre, prospective, single-arm, phase 2 study. Lancet Oncol 2020;21:978-88.

119 Morphosys US Inc. MONJUVI prescribing information. Available: https://www.accessdata.fda.gov/scripts/cder/daf/index.cfm?event= overview.process\&AppINo $=761163$

120 Mika T, Strate K, Ladigan S, et al. Refractory Epstein-Barr Virus (EBV)-related post-transplant lymphoproliferative disease: cure by combined brentuximab vedotin and Allogeneic EBV-speSpecific T-lyLymphocytes. Front Med 2019;6:295.

121 Hoffmann-La Roche, German C. L. L. Study Group. Fludarabine and cyclophosphamide with or without rituximab in patients with previously untreated chronic B-cell lymphocytic leukemia 2007 [updated July]. Available: https://ClinicalTrials.gov/show/ NCT00281918

122 Fischer K, Bahlo J, Fink AM, et al. Long-term remissions after FCR chemoimmunotherapy in previously untreated patients with CLL: updated results of the CLL8 trial. Blood 2016;127:208-15.

123 Hoffmann-La Roche, Biogen, Genentech, Inc. FCR Versus FC Alone in the Treatment of Chronic Lymphocytic Leukemia (CLL) in Relapsed Patients 2008 [updated July 23]. Available: https:// ClinicalTrials.gov/show/NCT00090051

124 Robak T, Dmoszynska A, Solal-Céligny P, et al. Rituximab plus fludarabine and cyclophosphamide prolongs progression-free survival compared with fludarabine and cyclophosphamide alone in previously treated chronic lymphocytic leukemia. J Clin Oncol 2010;28:1756-65. 
125 Pharmacyclics. IMBRUVICA prescribing information. Available: https://www.accessdata.fda.gov/scripts/cder/daf/index.cfm?event= overview.process\&AppINo $=205552$

126 National Cancer Institute. Ibrutinib and rituximab compared with fludarabine phosphate, cyclophosphamide, and rituximab in treating patients with untreated chronic lymphocytic Leukemiaor small lymphocytic lymphoma. Available: https://clinicaltrials.gov/ ct2/show/NCT02048813

127 Shanafelt TD, Wang XV, Kay NE, et al. Ibrutinib-Rituximab or chemoimmunotherapy for chronic lymphocytic leukemia. $N$ Engl $J$ Med 2019;381:432-43.

128 Hoffmann-La Roche, German C. L. L. Study Group, Genentech, Inc. CLL11: a study of obinutuzumab (ro5072759 ga101) with chlorambucil in patients with previously untreated chroniclymphocytic leukemia (Stage 1a) 2012 [updated July 1]. Available: https://ClinicalTrials.gov/show/NCT01010061

129 Goede V, Fischer K, Dyer MJ, et al, eds. Overall survival benefit of obinutuzumab over rituximab when combined with chlorambucil in patients with chronic lymphocytic leukemia and comorbidities: final survival analysis of the CLL11 STUDY. 23rd Congress of the European Hematology Association. Stockholm, Sweden, 2018.

130 Novartis Pharmaceuticals. Ofatumumab + Chlorambucil vs chlorambucil monotherapy in previously untreated patients with chronic lymphocytic leukemia 2013 [updated March 20]. Available: https://ClinicalTrials.gov/show/NCT00748189

131 Hillmen P, Robak T, Janssens A, et al. Chlorambucil plus ofatumumab versus chlorambucil alone in previously untreated patients with chronic lymphocytic leukaemia (complement 1): a randomised, multicentre, open-label phase 3 trial. Lancet 2015;385:1873-83.

132 Glaxo Grp, Ltd. ARZERRA prescribing information Basel, Switzerland. Available: https://www.accessdata.fda.gov/scripts/ cder/daf/index.cfm?event=overview.process\&AppINo=125326

133 GlaxoSmithKline, Genmab. Efficacy and safety of ofatumumab retreatment and maintenance treatment in patients with B-cell chronic lymphocytic leukemia (CLL) 2011 [updated September]. Available: https://ClinicalTrials.gov/show/NCT00802737

134 van Oers MHJ, Kuliczkowski K, Smolej L, et al. Ofatumumab maintenance versus observation in relapsed chronic lymphocytic leukaemia (prolong): an open-label, multicentre, randomised phase 3 study. Lancet Oncol 2015;16:1370-9.

135 Novartis Pharmaceuticals. Ofatumumab added to fludarabinecyclophosphamide vs fludarabine-cyclophosphamide combination in relapsed subjects with chronic lymphocytic leukemia 2014 [updated December 17]. Available: https://ClinicalTrials.gov/show/ NCT00824265

136 Robak T, Warzocha K, Govind Babu K, et al. Ofatumumab plus fludarabine and cyclophosphamide in relapsed chronic lymphocytic leukemia: results from the complement 2 trial. Leuk Lymphoma 2017;58:1084-93

137 GlaxoSmithKline. HuMax-CD20 in B-Cell chronic lymphocytic leukemia (B-CLL) patients failing fludarabine and alemtuzumab 2008 [updated May]. Available: https://ClinicalTrials.gov/show/ NCT00349349

138 Wierda WG, Kipps TJ, Mayer J, et al. Ofatumumab as single-agent CD20 immunotherapy in fludarabine-refractory chronic lymphocytic leukemia. J Clin Oncol 2010;28:1749-55.

139 Genzyme, a Sanofi Company, Sanofi. Efficacy/Safety of frontline alemtuzumab (Campath, MabCampath) vs chlorambucil in patients with progressive B-cell lymphocytic leukemia. Available: https:// ClinicalTrials.gov/show/NCT00046683

140 Hillmen P, Skotnicki AB, Robak T, et al. Alemtuzumab compared with chlorambucil as first-line therapy for chronic lymphocytic leukemia. J Clin Oncol 2007;25:5616-23.

141 Genzyme. Campath (alemtuzumab) prescribing information. Available: https://www.accessdata.fda.gov/scripts/cder/daf/index. cfm?event=overview.process\&App/No $=103948$

142 Osterborg A, Dyer MJ, Bunjes D, et al. Phase II multicenter study of human CD52 antibody in previously treated chronic lymphocytic leukemia. European Study group of CAMPATH-1H treatment in chronic lymphocytic leukemia. J Clin Oncol 1997;15:1567-74.

143 Keating MJ, Flinn I, Jain V, et al. Therapeutic role of alemtuzumab (Campath-1H) in patients who have failed fludarabine: results of a large international study. Blood 2002;99:3554-61.

144 Ferrajoli A, O'Brien SM, Cortes JE, et al. Phase II study of alemtuzumab in chronic lymphoproliferative disorders. Cancer 2003;98:773-8.

145 Rashidi A, Ebadi M, Cashen AF. Allogeneic hematopoietic stem cell transplantation in Hodgkin lymphoma: a systematic review and meta-analysis. Bone Marrow Transplant 2016;51:521-8.
146 Zahid U, Akbar F, Amaraneni A, et al. A review of autologous stem cell transplantation in lymphoma. Curr Hematol Malig Rep 2017;12:217-26.

147 Galaznik A, Huelin R, Stokes M, et al. Systematic review of therapy used in relapsed or refractory diffuse large B-cell lymphoma and follicular lymphoma. Future Sci OA 2018;4:FSO322.

148 Chen R, Zinzani PL, Lee HJ, et al. Pembrolizumab in relapsed or refractory Hodgkin lymphoma: 2-year follow-up of KEYNOTE-087. Blood 2019;134:1144-53.

149 Haverkos BM, Abbott D, Hamadani M, et al. PD-1 blockade for relapsed lymphoma post-allogeneic hematopoietic cell transplant: high response rate but frequent GVHD. Blood 2017;130:221-8.

150 ljaz A, Khan AY, Malik SU, et al. Significant risk of graft-versushost disease with exposure to checkpoint inhibitors before and after allogeneic transplantation. Biol Blood Marrow Transplant 2019;25:94-9

151 Merryman RW, Castagna L, Corradini P, et al. Safety and efficacy of allogeneic hematopoietic stem cell transplant after programmed cell death 1 (PD-1) / programmed cell death ligand 1 (PD-L1) blockade for classical Hodgkin lymphoma: analysis of a large international cohort. Blood 2019;134:775

152 Neelapu SS, Locke FL, Bartlett NL, et al. Axicabtagene Ciloleucel CAR T-cell therapy in refractory large B-cell lymphoma. $N$ Engl J Med Overseas Ed 2017;377:2531-44.

153 Li C, Zhang Y, Zhang C, et al. Comparison of CART19 and autologous stem-cell transplantation for refractory/relapsed nonHodgkin's lymphoma. JCl Insight 2019;5:e130195.

154 Hunter BD, Chen Y-B, Jacobson CA. Allogeneic stem cell transplantation and chimeric antigen receptor (CAR) T-cell therapy for the treatment of non-Hodgkin lymphoma. Hematol Oncol Clin North Am 2019;33:687-705.

155 Brentjens RJ, Davila ML, Riviere I, et al. CD19-targeted T cells rapidly induce molecular remissions in adults with chemotherapyrefractory acute lymphoblastic leukemia. Sci Trans/ Med 2013;5:177ra38.

156 Davila ML, Riviere I, Wang X, et al. Efficacy and toxicity management of 19-28z CAR T cell therapy in B cell acute lymphoblastic leukemia. Sci Transl Med 2014;6:224ra25.

157 Jin Z, Xiang R, Qing K, et al. The severe cytokine release syndrome in phase I trials of CD19-CAR-T cell therapy: a systematic review. Ann Hematol 2018:97:1327-35.

158 Topp MS, Goekbuget N, Zugmaier G, et al. Anti-CD19 bite Blinatumomab induces high complete remission rate in adult patients with relapsed B-Precursor all: updated results of an ongoing phase II trial. Blood 2011;118:252.

159 Rotz SJ, Leino D, Szabo S, et al. Severe cytokine release syndrome in a patient receiving PD-1-directed therapy. Pediatr Blood Cancer 2017;64:e26642.

160 Winkler U, Jensen M, Manzke O, et al. Cytokine-release syndrome in patients with B-cell chronic lymphocytic leukemia and high lymphocyte counts after treatment with an anti-CD20 monoclonal antibody (rituximab, IDEC-C2B8). Blood 1999;94:2217-24.

161 Maude SL, Laetsch TW, Buechner J, et al. Tisagenlecleucel in children and young adults with B-cell lymphoblastic leukemia. $N$ Engl J Med 2018;378:439-48.

162 Genentech. ACTEMRA prescribing information. Available: https:// www.accessdata.fda.gov/scripts/cder/daf/index.cfm?event= overview.process\&AppINo $=125276$

163 Grupp SA, Kalos M, Barrett D, et al. Chimeric antigen receptormodified T cells for acute lymphoid leukemia. $N$ Engl $J$ Med 2013;368:1509-18.

164 Lee DW, Gardner R, Porter DL, et al. Current concepts in the diagnosis and management of cytokine release syndrome. Blood 2014;124:188-95.

165 Neelapu SS, Tummala S, Kebriaei P, et al. Chimeric antigen receptor T-cell therapy - assessment and management of toxicities. Nat Rev Clin Oncol 2018;15:47-62.

166 Gust J, Hay KA, Hanafi L-A, et al. Endothelial activation and blood-brain barrier disruption in neurotoxicity after adoptive immunotherapy with CD19 CAR-T cells. Cancer Discov 2017;7:1404-19.

167 Baldo BA. Adverse events to monoclonal antibodies used for cancer therapy: focus on hypersensitivity responses. Oncoimmunology 2013;2:e26333-e.

168 Brudno JN, Kochenderfer JN. Toxicities of chimeric antigen receptor T cells: recognition and management. Blood 2016;127:3321-30.

169 National Cancer InstituteWoyach J. Duvelisib and nivolumab in treating patients with Richter syndrome or transformed follicular lymphoma. Available: https://ClinicalTrials.gov/show/NCT03892044

170 H. Lee Moffitt Cancer Center and Research Institute, Merck Sharp, Dohme Corp. Ibrutinib and PD-1 blockade in high risk lymphocytic 
leukemia 2021 [updated December]. Available: https://ClinicalTrials. gov/show/NCT03514017

171 Jankowitz R, Joyce J, Jacobs SA. Anaphylaxis after administration of ibritumomab tiuxetan for follicular non-hodgkin lymphoma. Clin Nucl Med 2008;33:94-6.

172 Maus MV, Haas AR, Beatty GL, et al. T cells expressing chimeric antigen receptors can cause anaphylaxis in humans. Cancer Immunol Res 2013;1:26-31.

173 Lenz H-J. Management and preparedness for infusion and hypersensitivity reactions. Oncologist 2007;12:601-9.

174 Dillman RO. Infusion reactions associated with the therapeutic use of monoclonal antibodies in the treatment of malignancy. Cancer Metastasis Rev 1999;18:465-71.

175 Gauthier J, Hirayama AV, Hay KA, et al. Comparison of efficacy and toxicity of CD19-specific chimeric antigen receptor T-cells alone or in combination with ibrutinib for relapsed and/or refractory CLL. Blood 2018;132:299.

176 Cruz CR, Hanley PJ, Liu H, et al. Adverse events following infusion of T cells for adoptive immunotherapy: a 10-year experience. Cytotherapy 2010;12:743-9.

177 Roselló S, Blasco I, García Fabregat L, et al. Management of infusion reactions to systemic anticancer therapy: ESMO clinical practice guidelines. Annals of Oncology 2017;28:iv100-18.

178 Cairo MS, Thompson S, Stern L, et al. Incidence of treatmentrelated, laboratory and clinical tumor lysis syndrome. Blood 2012;120:238.

179 Howard SC, Trifilio S, Gregory TK, et al. Tumor lysis syndrome in the era of novel and targeted agents in patients with hematologic malignancies: a systematic review. Ann Hematol 2016;95:563-73.

180 Belay Y, Yirdaw K, Enawgaw B. Tumor lysis syndrome in patients with hematological malignancies. Annals of Hematology 2017;95:563-73.

181 Naidoo J, Page DB, Li BT, et al. Toxicities of the anti-PD-1 and antiPD-L1 immune checkpoint antibodies. Ann Oncol 2015;26:2375-91.

182 Butterfield LH, Kaufman HL, Johnson DH, et al. SITC's Guide to Managing Immunotherapy Toxicity. 1 ed. New York: Springer Publishing Company.

183 Puzanov I, Diab A, Abdallah K, et al. Managing toxicities associated with immune checkpoint inhibitors: consensus recommendations from the Society for immunotherapy of cancer (SITC) toxicity management Working group. J Immunother Cancer 2017:5:95.

184 Couey MA, Bell RB, Patel AA, et al. Delayed immune-related events (dire) after discontinuation of immunotherapy: diagnostic hazard of autoimmunity at a distance. J Immunother Cancer 2019;7:165

185 Brahmer JR, Lacchetti C, Schneider BJ, et al. Management of immune-related adverse events in patients treated with immune checkpoint inhibitor therapy: American Society of clinical oncology clinical practice guideline. J Clin Oncol 2018;36:1714-68.

186 John AT, Bryan JS, Julie B, et al. Management of ImmunotherapyRelated toxicities, version 1.2019, NCCN clinical practice guidelines in oncology. J Natl Compr Canc Netw 2019;17:255-89.

187 Tao Q, Young LS, Woodman CBJ, et al. Epstein-Barr virus (EBV) and its associated human cancers--genetics, epigenetics, pathobiology and novel therapeutics. Front Biosci 2006;11:2672-713.

188 Shiels MS, Engels EA. Evolving epidemiology of HIV-associated malignancies. Curr Opin HIV AIDS 2017;12:6-11.

189 Nieters A, Kallinowski B, Brennan P, et al. Hepatitis C and risk of lymphoma: results of the European multicenter case-control study EPILYMPH. Gastroenterology 2006;131:1879-86.

190 Hill JA, Krantz EM, Hay KA, et al. Durable preservation of antiviral antibodies after CD19-directed chimeric antigen receptor T-cell immunotherapy. Blood Adv 2019;3:3590-601.

191 Centers for Disease Control and Prevention, Infectious Disease Society of America, American Society of Blood and Marrow Transplantation. Guidelines for preventing opportunistic infections among hematopoietic stem cell transplant recipients. MMWR Recomm Rep 2000;49(RR-10:CE1-7.

192 Uldrick TS, Gonçalves PH, Abdul-Hay M, et al. Assessment of the safety of pembrolizumab in patients with HIV and advanced Cancer-A phase 1 study. JAMA Oncol 2019;5:1332-9.

193 National Cancer Institute. Pembrolizumab in treating patients with hiv and relapsed, refractory, or disseminated malignant neoplasms 2020 [updated July 1]. Available: https://ClinicalTrials.gov/show/ NCT02595866

194 Gonzalez-Cao M, Morán T, Dalmau J, et al. Assessment of the feasibility and safety of durvalumab for treatment of solid tumors in patients with HIV- 1 infection: the phase 2 DURVAST study. JAMA Oncol 2020;6:1063-7.

195 Cook MR, Kim C. Safety and efficacy of immune checkpoint inhibitor therapy in patients with HIV infection and advanced-stage cancer: a systematic review. JAMA Oncol 2019;5:1049-54.
196 Spano J-P, Veyri M, Gobert A, et al. Immunotherapy for cancer in people living with HIV: safety with an efficacy signal from the series in real life experience. AIDS 2019;33:F13-19.

197 Chang E, Sabichi AL, Kramer JR, et al. Nivolumab treatment for cancers in the HIV-infected population. J Immunother 2018;41:379-83.

198 Rajdev L, Chiao E, Lensing S, et al. AIDS malignancy consortium (AMC) 095: a phase I study of ipilimumab (IPI) and nivolumab (NIVO) in advanced HIV-associated solid tumors (ST) with expansion cohorts in HIV-associated solid tumors and classical Hodgkin lymphoma (cHL). Journal of Clinical Oncology 2018;36:TPS44-TPS.

199 Abbasi A, Peeke S, Shah N, et al. Axicabtagene ciloleucel CD19 CAR-T cell therapy results in high rates of systemic and neurologic remissions in ten patients with refractory large B cell lymphoma including two with HIV and viral hepatitis. J Hematol Oncol 2020;13:1.

200 Abramson JS, Irwin KE, Frigault MJ, et al. Successful anti-CD19 CAR T-cell therapy in HIV-infected patients with refractory highgrade B-cell lymphoma. Cancer 2019;125:3692-8.

201 Barta SK, Lee JY, Kaplan LD, et al. Pooled analysis of AIDS malignancy consortium trials evaluating rituximab plus $\mathrm{CHOP}$ or infusional epoch chemotherapy in HIV-associated non-Hodgkin lymphoma. Cancer 2012;118:3977-83.

202 Boué F, Gabarre J, Gisselbrecht C, et al. Phase II trial of CHOP plus rituximab in patients with HIV-associated non-Hodgkin's lymphoma. $J$ Clin Oncol 2006;24:4123-8.

203 Yazici O, Sendur MAN, Aksoy S. Hepatitis C virus reactivation in cancer patients in the era of targeted therapies. World $J$ Gastroenterol 2014;20:6716-24.

204 El-Khoueiry AB, Sangro B, Yau T, et al. Nivolumab in patients with advanced hepatocellular carcinoma (CheckMate 040): an openlabel, non-comparative, phase 1/2 dose escalation and expansion trial. Lancet 2017;389:2492-502.

205 Zhu AX, Finn RS, Edeline J, et al. Pembrolizumab in patients with advanced hepatocellular carcinoma previously treated with sorafenib (KEYNOTE-224): a non-randomised, open-label phase 2 trial. Lancet Oncol 2018;19:940-52.

206 Lee M-Y, Chiou T-J, Hsiao L-T, et al. Rituximab therapy increased post-transplant cytomegalovirus complications in non-Hodgkin's lymphoma patients receiving autologous hematopoietic stem cell transplantation. Ann Hematol 2008;87:285-9.

207 Vallejo C, Ríos E, de la Serna J, et al. Incidence of cytomegalovirus infection and disease in patients with lymphoproliferative disorders treated with alemtuzumab. Expert Rev Hematol 2011;4:9-16.

208 Frisque RJ, White FA, Roos RP. The molecular biology of JC virus, causative agent of progressive multifocal leukoencephalopathy. In: Roos RP, ed. Molecular Neurovirology: pathogenesis of viral CNS infections. Totowa, NJ: Humana Press, 1992: 25-158.

209 Major EO, Amemiya K, Tornatore CS, et al. Pathogenesis and molecular biology of progressive multifocal leukoencephalopathy, the $\mathrm{JC}$ virus-induced demyelinating disease of the human brain. Clin Microbiol Rev 1992;5:49-73.

210 Focosi D, Tuccori M, Blandizzi C, et al. Incidence of progressive multifocal leukoencephalopathy in non-Hodgkin lymphoma patients treated with rituximab. Blood 2009;114:3675.

211 Power C, Gladden JG, Halliday W, et al. AIDS- and non-AIDSrelated PML association with distinct p53 polymorphism. Neurology 2000;54:743.

212 Brentjens R, Yeh R, Bernal Y, et al. Treatment of chronic lymphocytic leukemia with genetically targeted autologous $T$ cells: case report of an unforeseen adverse event in a phase I clinical trial. Mol Ther 2010;18:666-8.

213 National Cancer Institute. Surveillance, Epidemiology, and End Results Program. Cancer STAT facts: non-Hodgkin lymphoma. Cancer Stat Facts: Non-Hodgkin lymphoma, 2017. https://seer. cancer.gov/statfacts/html/nhl.html

214 Vose JM, Armitage JO, Weisenburger DD, et al. The importance of age in survival of patients treated with chemotherapy for aggressive non-Hodgkin's lymphoma. J Clin Oncol 1988:6:1838-44.

215 Bertini M, Boccomini C, Calvi R. The influence of advanced age on the treatment and prognosis of diffuse large-cell lymphoma (DLCL). Clin Lymphoma 2001;1:278-84.

216 Data on File. NIVO 254. Bristol-Myers Squibb Company, 2017.

217 Neelapu SS, Jacobson CA, Oluwole OO, et al. Outcomes of older patients in ZUMA-1, a pivotal study of axicabtagene ciloleucel in refractory large B-cell lymphoma. Blood 2020;135:2106-9.

218 Singh $\mathrm{H}$, Kanapuru B, Smith $\mathrm{C}$, et al. Fda analysis of enrollment of older adults in clinical trials for cancer drug registration: a 10-year experience by the U.S. food and drug administration. $J$ Clin Oncol 2017;35:10009. 
219 Ekström Smedby K, Vajdic CM, Falster M, et al. Autoimmune disorders and risk of non-Hodgkin lymphoma subtypes: a pooled analysis within the InterLymph Consortium. Blood 2008:111:4029-38.

220 Johnson DB, Sullivan RJ, Ott PA, et al. Ipilimumab therapy in patients with advanced melanoma and preexisting autoimmune disorders. JAMA Oncol 2016;2:234-40.

221 Leonardi GC, Gainor JF, Altan M, et al. Safety of programmed death-1 pathway inhibitors among patients with non-small-cell lung cancer and preexisting autoimmune disorders. J Clin Oncol 2018;36:1905-12

222 Abdel-Wahab N, Safa H, Abudayyeh A, et al. Checkpoint inhibitor therapy for cancer in solid organ transplantation recipients: an institutional experience and a systematic review of the literature. $J$ Immunother Cancer 2019;7:106.

223 Mott FE, Outcomes PR. Patient reported outcomes (pros) as part of value-based care can shape therapy guidelines: impact on emerging targeted agents and immunotherapy protocols in resource-limited regions. Oncol Ther 2017;5:69-74.

224 Community CS. The necessity of immunotherapy education for cancer patients Washington D.C. Available: https://www.cancersu pportcommunity.org/blog/2017/11/necessity-immunotherapyeducation-cancer-patients

225 Efficace F, Osoba D, Gotay C, et al. Has the quality of health-related quality of life reporting in cancer clinical trials improved over time? towards bridging the gap with clinical decision making. Ann Oncol 2007;18:775-81.

226 Osoba D. Health-Related quality of life and cancer clinical trials. Ther Adv Med Oncol 2011;3:57-71.

227 National Cancer Institute. Patient-reported outcomes version of the common terminology criteria for adverse events (PRO-CTCAE ${ }^{\mathrm{TM}}$ ). Available: https://healthcaredelivery.cancer.gov/pro-ctcae/

228 European Organisation for Research and Treatment of Cancer. Quality of life group website. Available: https://qol.eortc.org/

229 M. D. Anderson Cancer Center. The MD Anderson symptom inventory. Available: https://www.mdanderson.org/research/ departments-labs-institutes/departments-divisions/symptomresearch/symptom-assessment-tools/md-anderson-symptominventory.html
230 Porcu P, Hudgens S, Quaglino P, et al. Quality of life in cutaneous T-cell lymphoma subjects treated with anti-CCR4 monoclonal antibody mogamulizumab versus vorinostat: results from the phase 3 MAVORIC trial. Journal of Clinical Oncology 2018;36:7577.

231 Sidana S, Dueck AC, Burtis M, et al. Quality of life (QOL) in patients undergoing CAR-T therapy versus stem cell transplant (SCT). Journal of Clinical Oncology 2019;37:6594.

232 Ramos CA, Ballard B, Zhang $\mathrm{H}$, et al. Clinical and immunological responses after $\mathrm{CD} 30$-specific chimeric antigen receptor-redirected lymphocytes. J Clin Invest 2017:127:3462-71.

233 Rancea M, Monsef I, von Tresckow B, et al. High-dose chemotherapy followed by autologous stem cell transplantation for patients with relapsed/refractory Hodgkin lymphoma. Cochrane Database Syst Rev 2013:CD009411.

234 Santomasso B, Bachier C, Westin J, et al. The other side of car T-cell therapy: cytokine release syndrome, neurologic toxicity, and financial burden. Am Soc Clin Oncol Educ Book 2019;39:433-44.

235 Tran G, Zafar SY. Financial toxicity and implications for cancer care in the era of molecular and immune therapies. Ann Transl Med 2018;6:166

236 Chen Q, Jain N, Ayer T, et al. Economic burden of chronic lymphocytic leukemia in the era of oral targeted therapies in the United States. J Clin Oncol 2017;35:166-74.

237 Zafar SY, Peppercorn JM, Schrag D, et al. The financial toxicity of cancer treatment: a pilot study assessing out-of-pocket expenses and the insured cancer patient's experience. Oncologist 2013;18:381-90.

238 Meeker CR, Geynisman DM, Egleston BL, et al. Relationships among financial distress, emotional distress, and overall distress in insured patients with cancer. J Oncol Pract 2016;12:e755-64.

239 Kale HP, Carroll NV. Self-Reported financial burden of cancer care and its effect on physical and mental health-related quality of life among US cancer survivors. Cancer 2016;122:283-9.

240 Chabannon C, Kuball J, Mcgrath E, et al. Car-T cells: the narrow path between hope and bankruptcy? Bone Marrow Transplant 2017;52:1588-9.

241 Lin JK, Muffly LS, Spinner MA, et al. Cost effectiveness of chimeric antigen receptor T-cell therapy in multiply relapsed or refractory adult large B-cell lymphoma. J Clin Oncol 2019;37:2105-19. 
Correction: Society for Immunotherapy of Cancer (SITC) clinical practice guideline on immunotherapy for the treatment of lymphoma

Neelapu SS, Adkins S, Ansell SM, et al. Society for Immunotherapy of Cancer (SITC) clinical practice guideline on immunotherapy for the treatment of lymphoma. $J$ Immunother Cancer 2020;8:e001235. doi: 10.1136/jitc-2020-001235

In the Panel recommendations for Burkitt's lymphoma, the statement 'Options include rituximab+Lymphome Malins de Burkitt (R-LMB), rituximab+cyclophosphamide+doxorubicin+methotrexate / ifosfamide+etoposide+cytarabine (R-CODOXM/ IVAC), DA-R-EPOCH, rituximab+ German Multicenter Study Group for Adult Acute Lymphoblastic Leukemia Protocol (R-GMALL), and rituximab+cyclophosphamide+doxorubicin+dexamethasone+pegfilgrastim alternating with rituximab+methotrexate+cytarabine (R-HyperCAD)' has been corrected as below to add vincristine, omit pegfilgrastim and correct the acronym from 'R-HyperCAD' to 'R-HyperCVAD':

'Options include rituximab+Lymphome Malins de Burkitt (R-LMB), rituximab+cyclophosphamide+doxorubicin+methotrexate / ifosfamide +etoposide+cytarabine (R-CODOXM/IVAC), DA-R-EPOCH, rituximab+German Multicenter Study Group for Adult Acute Lymphoblastic Leukemia Protocol (R-GMALL), and rituximab+cyclophosphamide+vincristine+doxorubicin+dexamethasone alternating with rituximab+methotrexate+cytarabine (R-HyperCVAD).'

Open access This is an open access article distributed in accordance with the Creative Commons Attribution Non Commercial (CC BY-NC 4.0) license, which permits others to distribute, remix, adapt, build upon this work non-commercially, and license their derivative works on different terms, provided the original work is properly cited, appropriate credit is given, any changes made indicated, and the use is non-commercial. See http://creativecommons.org/licenses/by-nc/4.0/.

(C Author(s) (or their employer(s)) 2021. Re-use permitted under CC BY-NC. No commercial re-use. See rights and permissions. Published by BMJ.

J Immunother Cancer 2021;9:e001235corr1 . doi:10.1136/jitc-2020-001235corr1

Check for updates 